HAND PREFERENCE AND MLD

Running Head: HAND PREFERENCE AND MLD

\title{
Hand preference and Mathematical Learning Difficulties: New data from Greece, the United Kingdom, and Germany and two meta-analyses of the literature
}

Marietta Papadatou-Pastou ${ }^{\mathrm{a}, \mathrm{b}}$, Despoina-Athanasia Panagiotidou ${ }^{\mathrm{a}}$, Filippo Abbondanza $^{\mathrm{c}}$, Ursula Fischer ${ }^{\mathrm{d}}$, Silvia Paracchini ${ }^{\mathrm{c}}$, Giannis Karagiannakis ${ }^{\mathrm{e}}$

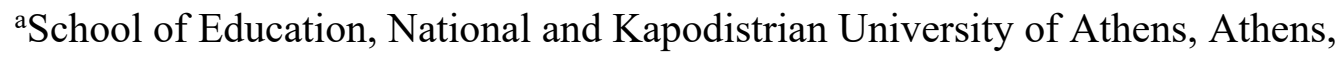
Greece

${ }^{b}$ Biomedical Research Foundation of the Academy of Athens, Athens, Greece

'School of Medicine, North Haugh, University of St Andrews, St Andrews, United Kingdom

${ }^{\mathrm{d} D e p a r t m e n t ~ o f ~ S p o r t ~ S c i e n c e, ~ U n i v e r s i t y ~ o f ~ K o n s t a n z, ~ K o n s t a n z, ~ G e r m a n y ~}$ e Department of Psychology, National and Kapodistrian University of Athens, Athens, Greece

*Correspondence to Dr. Marietta Papadatou-Pastou, School of Education, National and Kapodistrian University of Athens, 13A Navarinou Str, 106 80, Athens, Greece, Email: marietta.papadatou-pastou@seh.oxon.org

Draft version 3.0, 1.4.2021. This article may not exactly replicate the final version published in Laterality: Asymmetries of Brain, Behaviour, and Cognition $(10.1080 / 1357650 X .2021 .1906693)$. It is not the copy of record. 


\begin{abstract}
Increased rates of atypical handedness are observed in neurotypical individuals who are low-performing in mathematical tasks as well as in individuals with special educational needs, such as dyslexia. This is the first investigation of handedness in individuals with Mathematical Learning Difficulties (MLD). We report three new studies $(N=134 ; N=1,893 ; N=153)$ and two sets of meta-analyses (22 studies; $N=$ 3,667). No difference in atypical hand preference between MLD and Typically Achieving (TA) individuals was found when handedness was assessed with selfreport questionnaires, but weak evidence of a difference was found when writing hand was the handedness criterion in Study $1(p=.049)$. Similarly, when combining data meta-analytically, no hand preference differences were detected. We suggest that: (i) potential handedness effects require larger samples, (ii) direction of hand preference is not a sensitive enough measure of handedness in this context, or that (iii) increased rates of atypical hand preference are not associated with MLD. The latter scenario would suggest that handedness is specifically linked to language-related conditions rather than conditions related to cognitive abilities at large. Future studies need to consider hand skill and degree of hand preference in MLD.
\end{abstract}

Keywords: ALSPAC, meta-analysis, handedness, mathematical abilities, PC mouse preference 


\section{Introduction}

Within cognitive neuroscience there is growing attention on mathematical skills (e.g., Grabner \& Ansari, 2010) and associate difficulties, such as Mathematical Learning Difficulties (MLD) (e.g., Ashkenazi, Rosenberg-Lee, Tenison, \& Menon, 2012). A number of studies link the existence of MLD to right-hemispheric structural deficits, such as abnormalities in the microstructure of the white matter in the temporo-parietal cortex (Rykhlevskaia, Uddin, Kondos, \& Menon, 2009), as well as with functional deficits, such as weaker activation in the intraparietal sulcus (Ashkenazi et al., 2012; Price et al., 2007; Rotzer et al., 2009). Furthermore, support for the idea that atypical handedness, a measure informative of cerebral laterality for language, is associated with low mathematical ability in the general population (i.e., individuals without a formal diagnosis of MLD) is growing (Johnston et al., 2013). However, when it comes to individuals that have received an MLD diagnosis, no study has focused on the handedness patterns of their participants as its main research question, although a few do report handedness data for MLD individuals (e.g., Bucca, 2018; Jovanovic et al., 2014; Rubinstein \& Henik, 2006). The present study addresses the question of whether atypical handedness is associated with MLD for the first time, by presenting three new studies and by using meta-analytic methods to provide an overview of the literature.

Combining evidence using meta-analytic techniques, even if they were collected and reported in studies without having the meta-analysis research question as their primary objective, means that no data are wasted and new resources are not allocated to the investigation of the same research questions for which data are already available. Moreover, meta-analysis has increased statistical power and accuracy compared to each individual study. At the same time, it allows for the 
estimation of possible heterogeneity between the included studies, and, in the case heterogeneity does exist, to identify possible moderator variables (Egger \& Smith, 1997; Rosenthal \& Di Matteo, 2001; Walker, Hernandez, \& Kattan, 2008).

Furthermore, small study bias, a form of publication bias (the latter also referred to as ascertainment bias), can be investigated. Importantly, meta-analysis is vital in order to address the reproducibility issues troubling psychological research (e.g., Open Science Collaboration, 2015). Indeed, there is a growing body of meta-analytic literature on the existence of elevated levels of atypical handedness in conditions such as schizophrenia (Tran \& Voracek, 2015), autism spectrum disorder (ASD) (Markou, Ahtam, Papadatou-Pastou, 2017), deafness (Papadatou-Pastou \& Sáfár, 2016), and intellectual disability (Papadatou-Pastou \& Tomprou, 2015).

\subsection{Handedness and cerebral lateralization}

Handedness is the most prominent and widely studied behavioral asymmetry (Güntürkün \& Ocklenburg, 2017; Michel, Babik, Nelson, Campbell, \& Marcinowski, 2018; Papadatou-Pastou, 2011; Uomini \& Ruck 2018). It can be defined as the preference to use one hand over the other for manual tasks and/or the ability to perform these tasks more efficiently with one hand (Corey, Hurley, \& Foundas, 2001). Thus, handedness has two different manifestations, hand preference and hand skill, respectively. Two additional conceptualizations of handedness are direction and degree. Direction indicates whether an individual is right- or left-handed (with a third category oftentimes being a mixed-hander) either for preference or skill, whereas degree defines how strongly an individual prefers one hand to the other or how skilled one hand is compared to the other (Steenhuis \& Bryden, 1989). Worldwide the majority of individuals is right-handed and the prevalence of left-hand preference in the general population is estimated to be $10.6 \%$ (Papadatou-Pastou et 
al., 2020). Sex differences are observed in handedness, with males showing a higher prevalence (Papadatou-Pastou, Martin, Munafo, \& Jones, 2008). Cerebral lateralization for language in particular is the most extensively demonstrated functional laterality and has been shown to be associated, albeit weakly, with handedness (e.g., Bishop, Watt, \& Papadatou-Pastou, 2009; Floris et al., 2016; Gonzalez \& Goodale, 2009; Isaacs, Barr, Nelson, \& Devinsky, 2006; Khedr, Hamed, Said, \& Basahi, 2002; Sommer, Ramsey, Mandl, \& Kahn, 2002). The link between handedness and language lateralization was shown by a seminal study o by Knecht et al. (2000b) who found a linear increase in the prevalence of right-hemisphere language dominance with an increase in the degree of left-handedness from $4 \%$ in strongly right-handed individuals, to $15 \%$ in ambidextrous individuals and $27 \%$ in strong left-handers, using functional transcranial Doppler sonography (fTCD) in 326 healthy individuals. Mazoyer et al. (2014) claimed that most of the association between dominant hemispheres for language and hand use is due to left-handedness being found in strongly atypical individuals. Somers et al. (2015) showed that degree of hand preference and degree of language lateralization fit a cubic regression model, where stronger left-hand preference results in a higher chance for atypical language lateralization.

\subsection{Mathematical Learning Difficulty}

Many terms have been used to date to describe difficulties in mathematics. These include the terms dyscalculia (e.g., Hsieh, Lai, Lin, \& Huang, 2017), developmental dyscalculia (DD) (e.g., Träff, Olsson, Östergren, \& Skagerlund, 2016), mathematical learning difficulty (MLD) (e.g., Karagiannakis, Baccaglini-Frank, \& Papadatos, 2014), mathematics learning disability (e.g., Dennis, Sorrells, \& Falcomata, 2016), mathematical disability (e.g., Evans \& Ullman, 2016), mathematics 
disorder (e.g., American Psychological Association [APA], 1994), mathematical learning disorder (e.g., Capano et al., 2008), specific learning disorder with impairment in mathematics (e.g., APA, 2013), mathematics difficulties (e.g., Wong, Ho, \& Tang, 2017), mathematical impairment (e.g., Jastrzebski, Crewther, \& Crewther, 2015), low mathematical ability (e.g., Skeide, Evans, Mei, Abrams, \& Menon, 2018), arithmetic learning disability (e.g., Koontz, 1996), specific arithmetic difficulties (e.g., McLean \& Hitch, 1999), specific disorder of arithmetical skills (e.g., Hein, Bzufka, \& Neumärker, 2000), arithmetic deficiency (e.g., Greiffenstein \& Baker, 2002), calculation difficulties (e.g., Isaacs, Edmonds, Lucas, \& Gadian, 2001), and low numeracy (e.g., Galesic, Garcia-Retamero, \& Gigerenzer, 2009). Although the literature is riddled with different terminology we will use the term MLD to refer to learning difficulties in mathematics inclusively, following Karagiannakis et al. (2014).

Worldwide MLD has been estimated to affect between $1.3 \%$ to $13.8 \%$ of school-aged children with a mean of about $6 \%$ (Morsanyi, Bers, McCormack, \& McGourty, 2018). Studies have been conducted in a number of countries, such as the United States of America (5\%-8\%; Geary, 2004), Greece (6.3\%; Koumoula et al., 2004), Serbia (9.9\%; Jovanović et al., 2013), Germany (6.6\%; Hein et al., 2000), Belgium (3\% - 8\%; Desoete, Roeyers, \& De Clercq, 2004), Brazil (7.8\%; Bastos, Cecato, Martins, Grecca, \& Pierini, 2016), Slovakia (6.4\%; Kosc, 1974), Israel (6.5\%; Gross-Tsur, Manor, \& Shalev, 1996), and India (5.98\%, 5.54\%; Ramaa \& Gowramma, 2002). A review of 164 studies revealed a lack of consensus for an operational definition of MLD, as showcased by the variability in the assessment methods and in the cutoff criteria used to identify students with MLD (Lewis \& Fisher, 2016). Specifically, in $90 \%$ of the studies reviewed by Lewis and Fisher 
(2016) the cutoff scores for identification of students with an MLD ranged from the $2^{\text {nd }}$ percentile to the $46^{\text {th }}$ percentile, while the rest of the studies did not use achievement on a maths test as a criterion. This could explain the wide range of MLD prevalence found in the literature. When it comes to sex differences in MLD, White et al. (2016) showed that females are 32\% less likely than males to present MLD (White, Ruther, \& Kahn, 2016) and Reigosa-Crespo et al. (2012) reported a male to female ratio of 4:1. Other studies have also reported a similar sex difference in the prevalence of MLD (Devine, Soltész, Nobes, Goswami, \& Szücs, 2013; Koumoula et al., 2004).

\subsection{Handedness and MLD}

Only one study to date has investigated the relationship between senses and limbs laterality and MLD as its main research question, but without focusing on handedness per se (Jovanovic et al., 2014). It studied 140 fifth-grade pupils (83 with

dyscalculia [term as used by Jovanovic et al., 2014] and 57 typically developing) from all the elementary schools in Kragujevac, Serbia, and found no relationship between dominant hand and dyscalculia. However, there was evidence of a more frequent occurrence of mixed laterality in students with dyscalculia. Of note, this study was not published in the English language, but in Serbian.

In the absence of studies reporting on the handedness of individuals with MLD, we turn our attention to studies using general population samples that have reported on the mathematical abilities of different handedness groups. Johnston et al. (2013) used a large sample of 6,566 individuals aged less than 14 years old from the USA and showed that left-handers had lower test scores in mathematics, compared to their right-handed counterparts ( $7 \%$ of a standard deviation lower). The handedness of the participants was reported by their mothers and mathematical ability was assessed 
by the Peabody Individual Achievement Test (PIAT). Similar findings have also been reported by Johnston, Nicholls, Shah, and Shields, (2009) who studied an Australian sample of 4,942 children aged 4-5 years and found that both left- and mixed-handed children had lower performance in all measures of child development including mathematics, compared to right-handed ones. A recent series of five studies with 2,314 student participants in Italian schools reported that the variance in mathematic scores explained by handedness was between 3-10\%, although neither linear nor quadratic functions could capture this relationship sufficiently. Moreover, gender, age, and type of mathematical task influenced the shape of this relationship (Sala, Signorelli, Barsuola, Bolognese, \& Gobet, 2017).

Corballis, Hattie, and Fletcher (2008) further showed that ambidextrous individuals show worse performance than left- or right-handers on the arithmetic subscales of the New Zealand IQ Test, using a sample of 1,353 adults aged from 18 to over 60 years of age from New Zealand. Similar findings were reported by Crow, Crow, Done and Leask (1998) in their study totaling 11,700 11-year-olds from the UK. Rodriguez et al. (2010) studied 7,871 8-16 year-old children in Finland, and found that mixed-handers are more likely to develop mathematics-related problems. However, Sherman (1979) reported that handedness did not affect math achievement in a general population sample of 281 students in 9 th, 10 th, and 11 th grades.

Furthermore, mathematically talented children tend to have twice as many odds to be left-handed compared to typically achieving (TA) children (Bower, 1985). Benbow (1988) further supported that there is an increased prevalence of non-righthandedness among children with mathematical giftedness, while arithmetic skill was strongly associated with the skill of the left hand. However, a recent study of 7,525 
children in Ireland showed no evidence of an association between mathematical scores and handedness (O'Connell, 2018).

The possible relationship of atypical handedness and MLD is not just suggested by some published evidence, but there are also theoretical reasons making this investigation worthwhile. Recent work suggests that the same genes that are involved in structural laterality also contribute to behavioral laterality, as manifested by handedness, and neurodevelopmental disorders (Brandler \& Paracchini, 2014). The involvement of the same genes in handedness and neurodevelopmental disorders is further supported by the latest Genome Wide Association Studies (GWAS) on handedness, which found that genes that are involved in handedness formation are involved in cellular cytoskeleton and schizophrenia (Cuellar-Partida et al., 2020; Wiberg et al., 2018).

The putative relationship between handedness and MLD could be explained by left hemisphere dysfunction. Faults and malfunctions of the left hemisphere have been suggested to cause changes in the execution of tasks, difficulties in maintaining and recalling basic sizes, and problems in understanding the concept of numbers (Drigas \& Pappas, 2015). Shalev, Manor, Amir, Wertman-Elad and Gross-Tsur (1995) examined the relationship between arithmetic dysfunction and brain laterality in 25 children with developmental dyscalculia and found that dysfunction of both hemispheres hinder the learning process of arithmetics. Yet, left-hemisphere dysfunction can result in more severe difficulties suggesting that arithmetic functions are left-hemisphere dependent. Pinel and Dehaene (2010) in an fMRI study of 209 French adults, showed that performance of calculation tasks resulted in approximately equal levels of activations in both hemispheres, but with more extended activations in the left hemisphere. Isaacs et al. (2001) further showed using voxel-based 
morphometry that impaired calculation ability in adolescents of preterm birth was associated with less gray matter density in the left parietal lobe.

\subsection{Present scope}

The purpose of the present article is twofold: (i) to present new data on the handedness prevalence in individuals with MLD (Studies 1-3) and (ii) to synthesize statistically all old and new data on handedness levels in MLD, using meta-analytic techniques (Study 4). More specifically, Study 1 reports data from primary school students in Greece, and compares 45 MLD students with 89 TA students. Study 2 draws data from the ALSPAC longitudinal study, taking place in the UK and compares 445 MLD children with 1,448 TA children. Study 3 reports data from Germany on 19 children at risk of MLD and 134 not at risk of MLD on hand preference for writing and line tracing. Study 4 presents two sets of meta-analyses that combine the data of Studies 1-3 as well as data from 19 previously published studies or unpublished totaling 3,667 participants, although these latter studies were not designed to directly investigate handedness in MLD. The main goal is to explore and quantify the handedness prevalence in individuals with MLD compared to TA individuals. Another goal is to investigate heterogeneity among studies and possible sources of it. Candidate factors examined include year of publication of the study, location where the study took place, participant sex ratio, participant age, handedness classification, and instruments used to measure handedness and to diagnosed MLD, following similar meta-analyses which examined handedness in individuals with special educational needs (e.g., deafness; Papadatou-Pastou \& Sáfár, 2016; ASD; Markou et al., 2017; and intellectual disability; Papadatou-Pastou \& Tomprou, 2015). Moreover, small study bias is investigated.

\section{Study 1: Collection of primary data in Greece}




\subsection{Method}

\subsubsection{Participants}

This study included 134 fourth-grade students $(73$ female, mean age $=9.75$ yrs., $\mathrm{SD}=.33$ and 61 males, mean age $=9.77$ yrs., $\mathrm{SD}=.35$ ), recruited from public schools and after-school learning centers in the wider area of Athens. Students in the after-school learning centers faced math-related difficulties. Participants with a diagnosis of autism spectrum disorder, attention deficit disorder, or mental disability as well as participants with an extremely low raw Raven's Coloured Matrices score were excluded. All participants had raw scores of 13 or above (mean score $=27.88$, $\mathrm{SD}=4.42$, range $=13-35)$. Parents gave written informed consent prior to their child's participation in the study. The study was approved by the local ethics committee.

The MLD group consisted of 45 students (19 males, mean age $=9.79$ yrs., SD $=.32 ; 26$ females, mean age $=9.79$ yrs., $\mathrm{SD}=4.79)$ who were diagnosed as having MLD according to the NUCALC battery (von Aster, 2001; Koumoula, et al., 2004). The TA group included 89 students without MLD (42 males, mean age $=9.79$ yrs., $\mathrm{SD}=.37 ; 47$ females, mean age $=9.73, \mathrm{SD}=.29)$. Groups were matched for age, $t(132)=.64, p=.52, \operatorname{sex}, \chi^{2}(1)=.30, p=.59$, and intelligence according to WISC-III Vocabulary subscales, $t(132)=-1.16, p=.25$, and WISC-III Digit Span, $t(132)=-.26$, $p=.79$, but not according to WISC-III Digit Span (reverse order), $t(132)=-4.16, p<$ .001 , and Raven's Coloured Matrices, $t(132)=-5.04, p<.001$.

\subsubsection{Material}

Neuropsychological Test Battery for Number Processing and Calculation for Children (NUCALC): Mathematical abilities were assessed using the Greek standardized version of the NUCALC (Koumoula et al., 2004). The NUCALC is an untimed paper-and-pencil arithmetic fluency test which consists of six subtests: 
Dictation of Numbers, Mental Addition, Reading Numbers, Oral Comparison, Problem Solving, and Written Comparison. Children with low achievement, i.e. below the 30th percentile (which corresponds to a score of 60), were classified as MLD students. The cut-off score was based on the Greek standardized norms of the NUCALC battery.

Wechsler Intelligence Scale for Children (WISC) - III: The Vocabulary and Digit Span subscales from the WISC-III (Wechsler, 1991) were administered. For the Vocabulary scale, each student was asked to define a provided word. For the Digit Span scale, each student was asked to repeat orally sequences of numbers, as heard and in reverse order.

Raven's Coloured Matrices (Sideridis, Antoniou, Simos \& Mousaki, 2015): The non-verbal IQ of participants was measured with Raven's Coloured Matrices Test. This is a normed untimed visual-spatial reasoning test for children in the age range of 4-12 years. Children saw a coloured pattern and were asked to select the missing piece out of 6 options.

Handedness inventory: A 4-item questionnaire was used for hand preference assessment, including hand used for writing, drawing, throwing a stone, and using a computer mouse. A recent meta-analysis showed that short questionnaires give the same handedness estimates as longer ones and should thus be preferred (PapadatouPastou et al., 2019). The participants could respond with the right hand (scored with 0 ), both hands (scored with 1), or the left hand (scored with 2). A handedness index describing degree of hand preference was calculated by adding the responses to the questionnaire, with higher scores indicating stronger left-handedness. Moreover, participants were grouped into left-handers (scores 4-8) and right-handers (scores 0- 
3), with a second grouping consisting of left-handers (scores 6-8), mixed-handers (scores 3-5) and right-handers (scored 0-2).

\subsubsection{Procedure}

Each child was tested individually at their school or afterschool learning center. All assessments were conducted by trained research assistants in the following order: Vocabulary, Raven, Digit span, Handedness, and NUCALC. The duration of the evaluation was approximately 45 minutes.

\subsubsection{Statistical analysis}

All analyses were performed using the Statistical Package for the Social Sciences (SPSS) v. 25 (IBM Corporation, 2017). A univariate ANOVA was run with sex (male and female) and presence of MLD (MLD and TA) as the grouping factors and with the continuous handedness score as the dependent variable. The $\eta^{2}$ statistic was used as an estimate of power. In order to test if handedness frequencies differ between the MLD and TA group, chi square tests were used. Moreover, Pearson's $r$ was used to test for a correlation between the score in the NUCALC test and the continuous handedness score of the participants.

\subsection{Results}

Tables 1 and 2 present the handedness data for both groups of participants (MLD and TA), broken down by sex. The two groups were not found to differ with regards to the frequency of left- and right-handers they include, $\chi^{2}(1)=1.30, p=.26$. Differences with regards to the frequency of left-, mixed-, and right-handers could not be tested as there were two cells with $n<5$. However, when only writing hand was entered into the analysis (merging the participants who had responded "both hands" with those that had selected the left hand), then there was weak evidence of a relationship, $\chi^{2}(1)=3.89, p=.049$. Moreover, there was statistical evidence that the 
NUCALC score correlates with the handedness score, over the whole sample, $r=$ $.35, p<.001$. Such evidence was further found within both groups, $r=-.49, p=.001$ and $r=-.22, p=.04$, for the MD and TA groups, respectively, thus the correlation was stronger within the MLD group. Moreover, the correlation held true for both males, $r=-.33, p=.009$, and females, $r=-.35, p=.002$. A $2 \times 2$ ANOVA was run with sex (male or female) and presence of MLD (MLD and TA) as the grouping factors and with handedness score as the dependent variable. No main effects of sex, $F(1,130)=.91, p=.34, \eta^{2}=.01$, presence of MLD, $F(1,130)=1.01, p=.32, \eta^{2}=.01$, or interaction between sex and presence of $\operatorname{MLD}, F(1,130)=.17, p=.68, \eta^{2}=.01$, were found.

All data and analysis code is available at https://osf.io/p4e9h/.

Please insert Tables $1 \& 2$ about here

\subsection{Discussion}

Handedness data where compared between a group of students with MLD and an age- and sex-matched group of TA students, all attending the 4th grade of primary school. Handedness was operationalized as hand preference, using a 4-item self-report inventory.

Findings provide a mixed picture. When grouping the students into left- and right-handers using the midpoint of a handedness index that was calculated using all four items, then handedness frequency was not found to differ between MLD and TA students. However, when only writing hand was taken into account (merging those who use their left hand with the participant who reported using both of her hands for writing), then there was evidence of a difference, albeit weak $(p=.049)$. A $2 \times 2$ 
ANOVA did not show any differences in the continuous handedness score between males and females or between MLD and TA students, nor an interaction between sex and mathematical achievement. Yet, when the continuous mathematical achievement score that was calculated using the NUCALC test was correlated with the continuous handedness score, then the evidence of this relationship was strong.

The present findings are representative of the handedness literature in that it is riddled with different assessment criteria for handedness as well as different cut-off points for the handedness categories that are employed in different studies. This lack of a consensus in the assessment of handedness has been pointed out as a factor that contributes to the discrepancies in the literature when discussing the relationship of handedness with other variables, such as intelligence (Papadatou-Pastou, 2018), or the prevalence rates of handedness in the general population (Papadatou-Pastou et al., 2020). In addition, the study illustrates how challenging it is to interpret handedness effects in small samples, even more so as only a small percentage of the sample presents with atypical handedness. Therefore, chance findings could be mistaken for true effects and vice versa.

\section{Study 2: Data from the ALSPAC longitudinal study}

\subsection{Method}

\subsubsection{Participants}

ALSPAC is a longitudinal cohort representing the general population living in the Bristol area. Pregnant women resident in the county of Avon, UK, with expected dates of delivery from 1st April 1991 to 31st December 1992 were invited to take part in the study, resulting in 14,062 live births and 13,988 children who were alive at 1 year of age (Boyd et al., 2013; Fraser et al., 2013). From age seven, all children were invited annually for assessments on a wide range of physical, behavioural and 
neuropsychological traits. Informed written consent was obtained from the parents after receiving a complete description of the study at the time of enrolment into ALSPAC, with the option to withdraw at any time. Ethical approval for the present study was obtained from the ALSPAC Law and Ethics Committee and the Local Research Ethics Committees. The ALSPAC study website contains details of all the data that is available through a fully searchable data dictionary (http://www.bris.ac.uk/alspac/researchers/data-access/data-dictionary/).

The cohort includes a vast collection of phenotypic data for probands at different time points, including those relevant to this study, such as cognitive assessment, educational attainment, and handedness (Buenaventura Castillo et al., 2020). For the scope of this study we applied the following exclusion criteria: i) a performance IQ $<85$ to exclude possible conditions that might affect mathematical abilities as a secondary effect (Wechsler et al., 1992), ii) presence of other neurodevelopmental conditions (i.e., ASD, dyslexia, developmental language disorder, or ADHD) as defined before in the ALSPAC cohort (Newbury et al., 2014; Scerri et al., 2011), iii) individuals who had missing data for any of the measures necessary for this study. A total of 2,894 individuals (1,557 females, 1,337 males) entered the study. The MLD group consisted of 445 individuals (mean age $=11.2$ yrs., $\mathrm{SD}=.31 ; 184$ males [mean age $=11.2$ yrs., $\mathrm{SD}=1.69$ ] and 261 females [mean age $=11.2$ yrs., $\mathrm{SD}=1.62$ ], referring to the age at which probands undertook the math tests) selected for a Mathematical Achievement (MA) score (see below for details of the test) $<-1$ SD. Three individuals (females) presented inconsistent handedness between two time points (at age 7 and 11) and were excluded from the primary analysis (Table 3). The TA group included 1,664 individuals with a MA score $>0$ (mean age $=11.2$ yrs., $\mathrm{SD}=.31 ; 800$ males and 827 females, excluding 9 
individuals reported with dyscalculia on a questionnaire filled by the mother). Since the MLD and TA groups were not matched for gender, a random gender-matching was carried out by eliminating 165 males in the TA group. This resulted in a sample of $N=1,448$ TA individuals (mean age $=11.2$ yrs., $\mathrm{SD}=.31 ; 590$ males [mean age $=$ 11.2 yrs., $\mathrm{SD}=.311]$ and 858 females [mean age $=11.2$ yrs., $\mathrm{SD}=.309])$. Matching for gender was considered necessary, as robust sex differences in handedness have been documented (Papadatou-Pastou et al., 2008). Groups were not matched for age (measured in months ; MLD group was 1.6 months younger than the TA one, Figure 1) at which the MA test was undertaken, $t(1891)=-.6117, p<0.001$, WISC-III Digit Span, $t(1847)=-13.034, p<.001$, WISC-III Vocabulary, $t(835.79)=-13.333, p<$ .001 , and total IQ, $t(932.12)=-24.482, p<.001)$.

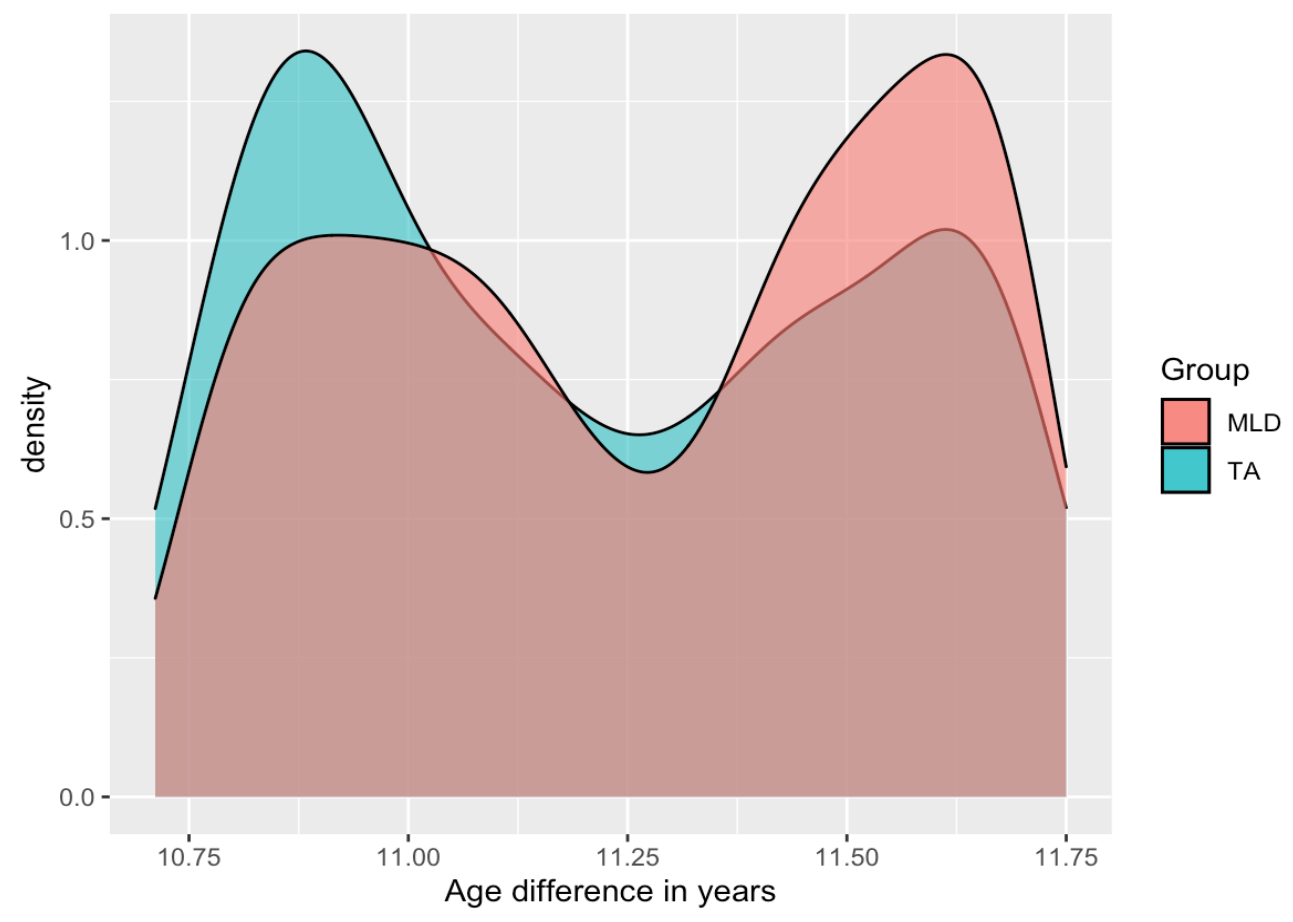

Figure 1. Age in difference between MLD and TA group

\subsubsection{Material}

Wechsler Intelligence Scale for Children (WISC) - III: The Vocabulary and Digit Span subscales from the WISC-III were used (Woolger, 2001) as described for 
Study 1. Total IQ was calculated as the sum of the verbal and performance IQ subtests (5 subtests each).

Math Achievement (MA) score: The math achievement score was computed as the sum of the Key Stage 2 tests, consisting of two written maths tests (45 minutes each) and a mental arithmetic test (20 minutes) (Nunes, Bryant, Barros, \& Sylva, 2012; Pettigrew et al., 2015). The Key Stage 2 tests were designed by the British government to measure school achievement and were conducted and scored by teachers. The three tests assess arithmetic and mathematical reasoning, through problem-solving (i.e., "A box contains trays of melons. There are 15 melons per tray. Each box has 3 trays. How many melons can a farmer sell?") and graph interpretation (i.e., counting the faces of a 3D geometric figure).

Handedness: Self-reported hand preference for writing was collected at two time points (age 7 and 11) as a categorical trait ('Right' or 'Left').

More details of all the data are available through a fully searchable data dictionary and variable search tool (http://www.bristol.ac.uk/alspac/researchers/our-data/).

\subsubsection{Statistical analysis}

All analyses were performed using R Studio v.3 (R Core Team, 2018). Chisquare test was used to compare the frequency of handedness in the MLD and TA groups. The $t$-test and the Welch $t$-test (a $t$-test for distributions with unequal variances) were used to compare the differences of age, WISC-III Vocabulary, total IQ, and Digit Span between the MLD and TA groups.

\subsection{Results}

Table 3 presents the handedness data for both the MLD and the TA groups, excluding individuals with inconsistent handedness, broken down by sex. Hand preference (right- vs. left-handedness) was not found to be associated with 
participants' group (presence of MLD, $\chi^{2}(1)=.38421, p=.53$ ) and, within the MLD group, with gender $\left(\chi^{2}(1)=.055063, p=.81\right)$. When looking in the more severe subgroups (MA<-1.75SD) left-handedness frequency was slightly higher (11.5\%), with this trend mainly driven by females (12.3\%) (Table 4), but the data points were not sufficient for statistical comparisons with the TA group. All analysis code is available at https://osf.io/p4e9h/.

\subsection{Discussion}

Hand preference for writing was compared between individuals with MLD and a sex-matched group of TA probands. The results suggest that handedness frequency does not differ between the MLD and TA groups $(p=.53)$. The presence of a gender difference for math abilities is debated in the current literature, with some studies supporting that such a sex-gap exists (Cimpian, Lubienski, Timmer, Makowski, \& Miller, 2016), whereas others finding little or no evidence (Lindberg, Lindberg, Hyde, Petersen, \& Linn, 2010; Miller \& Bichsel, 2004; for a review see Devine et al., 2013). Sex was thus investigated for association with hand preference within the MLD group, but no association was found $(p=.81)$. In other terms, the frequency of male and female left-handers is similar in the MLD and TA groups.

Several studies further report a slight advantage of older students in mathematics in Grades 4, 7, 8, and 9 (e.g., Cobley et al., 2009; Kawaguchi, 2011). In the case of the present study, the MLD and TA groups were not matched for age $(p<$ .001 ), with the TA individuals being on average 7 weeks older (Figure 1). This showcases how even in large samples with detailed phenotypes (e.g., age measured in weeks, not years), as it was the case here, it remains a challenge to reach homogeneity across cases/controls. Therefore, the possibility of a bias in how the groups were defined exists. In other words, some children in the MLD group might be lower 
performing on the mathematical achievement tests because they are younger rather than because they present with MLD.

\section{Study 3: Collection of primary data in German kindergarten children}

\subsection{Method}

\subsubsection{Participants}

As part of a larger study investigating children's mathematical and fine motor skills, 155 children from kindergartens located in rural areas of Southern Germany were tested. Two children had to be excluded from the analysis due to missing data. None of the remaining children was diagnosed with or displayed any signs of neurodevelopmental or physical disorders. The final sample consisted of 74 girls $(M=$ 5.4 years, $S D=9.2$ months $)$ and 79 boys ( $M=5.5$ years, $S D=8.2$ months $)$ from middle-class families. Socioeconomic status was approximated from parents' educational attainment, with $38 \%$ of mothers and $39 \%$ of fathers reporting having completed tertiary education (slightly higher than the national German average of $32 \%$; OECD, 2019). Prior to the study, parents gave their informed consent, and children were allowed to stop participating at any point during the study. The study was conducted in accordance with the declaration of Helsinki.

To determine whether children were at risk of developing MLD, we used a standardized math ability score (see below for a description of the calculation of this score). Based on this standardized math ability score, children were then classified as at risk or not at risk for developing MLD. We classified those children that were at least $1 \mathrm{SD}$ under the mean performance of their age group as being at risk. The at risk group consisted of 19 children $(10$ males, mean age $=5.43$ yts., $\mathrm{SD}=.79 ; 9$ females, mean age $=5.15$ months, $\mathrm{SD}=.75)$, and the not at risk group consisted of 134 children $(67$ males, mean age $=5.52$ months, $\mathrm{SD}=.68 ; 63$ females, mean age $=5.41$ 
months, $\mathrm{SD}=.75)$. Groups were matched for age, $t(151)=.96, p=.337$, and sex, $\chi^{2}(1)=.01, p=.926$, but not for backward visual working memory Span, $t(151)=$ 4.13, $p<.001$, and conceptual thinking, $t(151)=3.31, p<.01$.

\subsubsection{Material}

\subsubsection{Measures of handedness}

Because handedness in young children is often not yet fully developed, handedness was measured via two different measures.

Hand preference: First, children's preferred writing hand was recorded twice: Once when they attempted to write their first name and once when they performed a line tracing task. The performance scores of these tasks were not relevant to the current research question and are not reported here.

Degree of hand skill: In order to receive a continuous measure of children's handedness, we also measured children's tapping speed with the left and right hand. Children performed a tapping task for 10 seconds once with their right and once with their left index finger on a touchscreen using the app 'Tap Test Pro' for Android (Hesesport, 2015). This app records the number of taps performed on the screen with the index finger and only starts recording once the first tap is made. From this task, we calculated children's relative degree of hand skill similar to the Relative Hand Skill ('PegQ') reported by Brandler et al. (2013). The formula used for this

calculation was $2(\mathrm{R}-\mathrm{L}) /(\mathrm{R}+\mathrm{L})$, and resulted in a measure of the degree of hand skill in which positive values indicated a faster right hand and negative values indicated a faster left hand performance.

\subsubsection{Measures of precursor numerical abilities}

The three numerical ability measures used in this study were chosen based on their predictive value for future mathematical development, as well as on previous 
reports of these abilities being impaired in children with MLD. According to longitudinal studies, precursor numerical abilities can reliably predict both future mathematical development as well as the development of MLD in elementary school (Geary, Bailey, Littlefield, Wood, Hoard, \& Nugent, 2009; Stock, Desoete, \& Roebers, 2010). Among other abilities, kindergarten children's procedural and conceptual counting skills were found to be predictive of their later MLD diagnosis (Stock, Desoete, \& Roebers, 2010), with the understanding of ordinality and cardinality playing a particularly important role in long-term mathematical development (Chu, vanMarle, \& Geary, 2015; Lyons, Price, Vaessen, Blomert, \& Ansari, 2011). Therefore, ordinal counting and cardinal magnitude understanding were tested via finger-based tasks. Additionally, as most children with MLD display problems with arithmetic operations (e.g., Butterworth, 2001), a subtest from a dyscalculia test battery (German Version of the TEDI-MATH, Kaufmann et al., 2009) was used to test children's early calculation skills.

Finger counting: To assess children's finger counting ability, children were asked to count aloud while using their fingers. This task tested whether children were capable of assigning each finger the correct counting word and using the counting sequence correctly. All numbers from 1 to 10 were tested in a mixed order to keep children from simply adding another finger for each subsequent number. For each correctly counted-to number, children were awarded one point. For the analysis, the sum of correctly counted-to numbers was used as the dependent variable, with a maximum score of 10 .

Showing numbers with fingers: As for the finger counting test, children were asked to show the experimenter a number using their fingers. This task required children to instantaneously show a number with their fingers instead of counting up to 
it, and therefore tested their cardinal understanding of numbers. Again, all numbers from 1 to 10 were tested in a mixed order. For each correctly shown number of fingers, children received a point, again resulting in a maximum score of 10.

Arithmetic operations: Children's calculation abilities were tested using the Arithmetic Operations with Object Depictions subtest from the German version of the standardized test battery TEDI-MATH (Kaufmann et al., 2009). For this test, children are presented with pictures of, for example, six balloons, of which four are red and two are blue. They are then verbally presented with an addition or subtraction problem, for example: "How many are 4 balloons plus 2 balloons?". While reading the problem, the experimenter points to the respective blue and red balloons to help the child with the decision. Children are presented with three addition and three subtraction problems and are allowed to solve them in any way they choose. Each correctly solved problem was rewarded with one point, resulting in a maximum of 6 points.

\subsubsection{Control variables}

Cognitive abilities: To control for children's domain general cognitive abilities, we used the conceptual thinking subtest of the KABC-II (Kaufman \& Kaufman, 2015). This subtest measures a child's ability to reason about classifications of things and objects in a nonverbal format. Children are presented with four or five pictures and have to decide which one of the pictures does not fit with the set (e.g., three red umbrellas and one yellow umbrella). Children give their response by pointing at the chosen picture and are awarded one point per correct response. In total, the subtest consists of 28 items, but testing stops when a child answers four out of five consecutive items incorrectly. The sum score was entered as a covariate in the analysis. 
Visual working memory: Children's visual working memory was assessed via a backward Corsi block-tapping task, in which children had to memorize and replicate a visually presented sequence in the reverse order. The task was conducted using a wooden board with nine wooden cubes $(3 \mathrm{~cm} \times 3 \mathrm{~cm} \times 3 \mathrm{~cm})$ glued onto it in a nongeometrical pattern (replicated after the layout presented in Kessels et al., 2000). First, the experimenter tapped the cubes in a certain order at a speed of approximately one cube per second. The child was instructed to wait until after the experimenter was finished, and then tap the cubes in the reversed order. Two items were presented per span length, with difficulty starting at two blocks and increasing up to seven blocks. If the child successfully replicated at least one of the two items of a given length, testing continued with the length increasing by one. As soon as two items of the same length were replicated incorrectly, testing was stopped. The longest successfully replicated span - not the number of correctly remembered items - was used in the analysis as the child's visual working memory span.

\subsubsection{Procedure}

Children were tested individually by student research assistants in separate rooms in their respective kindergartens. Each child was tested on two separate days to avoid overexertion. No testing session took longer than 40 minutes. The study was presented as a story about an otter that wanted to find out what the children had already learned. At the end of the study, children received a keychain depicting the otter as a reward for helping the otter learn. Because it is as of yet unclear at which age handedness has predictive value for children's mathematical performance, this study was conducted before the start of formal schooling to assess whether children at risk of developing MLD would show differences in the distribution of their handedness. 


\subsubsection{Statistical analysis}

All analyses were performed using SPSS v. 25 (IBM Corporation, 2017). Prior to the statistical analysis, all measures were $z$-standardized. For mathematical abilities, a composite score was calculated by first brining all measures to the same scale so that all of them were weighted equally and then a sum score was created. This sum score was then standardized for younger children and older children (median split) separately to account for the large age span in our sample. Three analyses were performed: First, the distributions of left- and right-handers over the two MLD groups were compared via a Chi-square test. We then calculated a $t$-test to compare children at risk with children not at risk for developing MLD on their degree of hand skill. Then, we calculated a Pearson correlation coefficient between degree of hand skill and mathematical abilities.

\subsection{Results}

Only 5 children wrote with their left hand, and one child switched hands in between the two hand preference assignments (writing hand and hand used for line tracing; inconsistent handedness) and was excluded from further analysis comparing left- and right-handed children. Because of the small overall number of left-handed children, analyses were not conducted separately for male and female participants. There was evidence of a difference in the degree of hand skill between left- $(M=-.05)$ and righthanded children $(M=.23), t(150)=2.05, p=.042$.

The numbers of male and female participants in the MLD and handedness groups are presented in Table 5. Descriptive statistics are presented in Table 6. 
Considering the distribution of participants across MLD and hand preference groups, the chi square statistic revealed no evidence of associations between hand preference and MLD status, $\chi^{2}(1)=3.575, p=.059$. There was also no evidence of a difference between the two groups with regard to degree of hand skill, $t(151)=-.40, p=.692$.

Degree of hand skill was not correlated with the math ability score, $r=.012, p=.883$.

\subsection{Discussion}

The results of Study 3 indicate that in early childhood, before the onset of formal schooling, handedness does not seem to play a major role in children's numerical abilities. Children who were classified as being at risk for developing MLD did not show a different degree of handedness than children not at risk for developing MLD. Also, the degree of hand skill measure reported here was not associated with children's numerical performance.

Three possible explanations can account for these findings: The first is that handedness does not play a role in the early developmental stages of numerical abilities, and that instead, cognitive abilities and numerical precursor abilities are more relevant. The second explanation could be that the degree of hand skill measure calculated from the tapping task does not provide a sensitive enough measurement of children's handedness, at least not in our sample. The third one could be that the size of the sample was too small to capture any handedness effects. Future studies could therefore make use of different, maybe less speed-based and more accuracy-based measurements of handedness in larger samples.

\section{Study 4: Meta-analysis}

\subsection{Method}

Two sets of analyses took place 1) meta-analysis set 1 included meta-analyses of studies that provided handedness data on individuals with MLD as well as TA 
individuals acting as controls, 2) meta-analysis set 2 included meta-analyses of studies that reported data on the handedness prevalence in individuals with MLD (irrespective of the presence of a control group).

\subsubsection{Locating studies}

The studies that were entered into the meta-analyses were located via the online databases Pubmed MEDLINE, PsychINFO, HEALLink, Scopus and National Documentation Centre using the search terms (handedness OR "hand preference" OR "hand skill”) AND (dyscalculia OR math*). All fields were searched for the target words with no time restriction. The cited literature of all articles that were eligible for inclusion was scanned as well. In addition, e-mail requests for unpublished data were sent to the authors of the included articles (when e-mail addresses could be retrieved), in order to ensure that no study was left out of the meta-analyses. The number of the abstracts screened was 376 (299 articles were excluded at this stage). The number of full text articles assessed for eligibility was 77 . Nineteen studies were included in the meta-analyses, in addition to the three studies reported in the present article. Details about the method of literature search and study selection are shown in Figure 2. Data extraction was performed by MPP and DP (intercoder agreement 97\%). Any inconsistencies were resolved through discussion. Data collection ended in April 2020. The meta-analyses were conducted following the guidelines of the PRISMA statement (Moher et al., 2009).

Figure 2. Flow diagram for the search and inclusion criteria for studies in the metaanalyses. The figure was created according to the guidelines of the PRISMA statement (Moher, et al., 2009). 


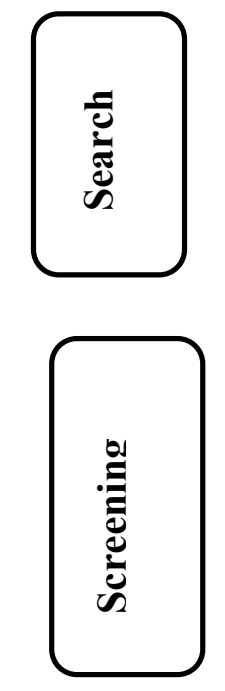

- Electronic databases (Pubmed, Scopus, HEALLink, PsycINFO, National Documentation Centre)

- Scanning reference lists

- E-mail requests for unpublished data

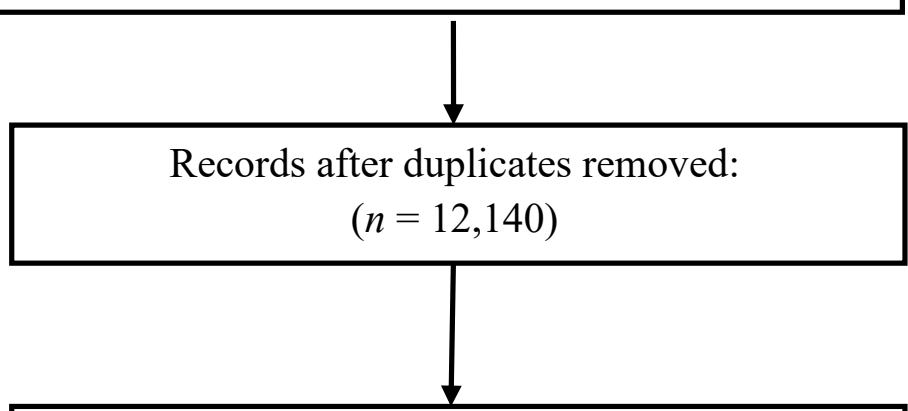

- Studies had to measure handedness in individuals with mathematical learning difficulties.

- Studies whose participants had comorbidity with other difficulties/disorders were excluded.

- Studies whose participants were selected on the basis of their handedness were excluded.

- Studies had to be published in English or Greek, or otherwise a translation needed to be provided.
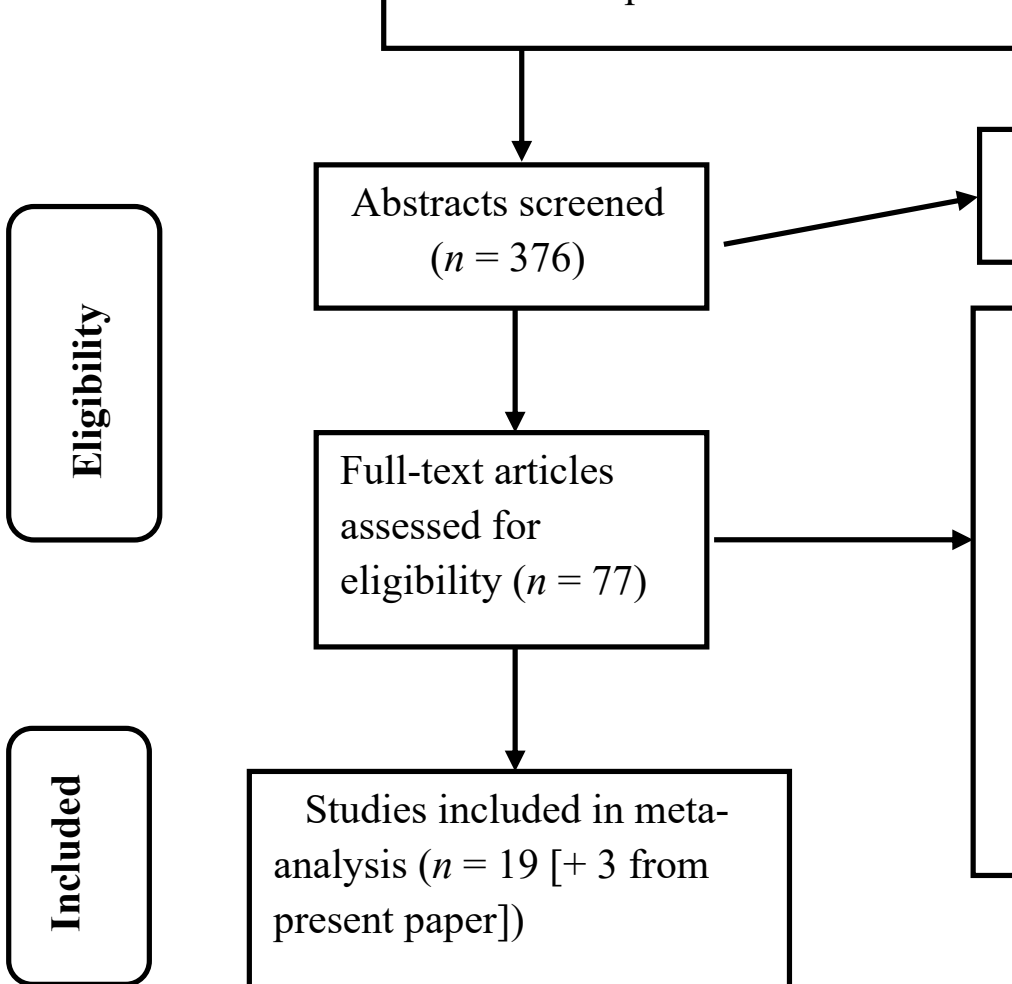

Abstracts excluded $(n=299)$

Full-text articles excluded $(n=58)$

Reasons:

- Comorbidity

- Selection of participants on the basis of handedness

- Absence of handedness or mathematical difficulties

- Not useable arithmetic data Studies included in meta-

- Same sample analysis $(n=19[+3$ from present paper]) 


\subsubsection{Study selection}

The following criteria were set for inclusion of a study in the meta-analyses:

Participants: To be considered for inclusion, studies had to measure handedness in participants who were assigned to a MLD group after their mathematical ability was objectively measured (terms used in the included studies were developmental dyscalculia, MLD, low mathematic score, arithmetic deficiency, mathematically impaired, low mathematical ability, but as stated earlier the term MLD is here used inclusively). In the cases where the presence of MLD was selfreported, studies were excluded (e.g., Hoffmann, Mussolin, Martin, \& Schiltz, 2014; Rodriguez et al., 2010).

Absence of comorbidity: Studies including participants with MLD who also presented with aphasia (e.g., Semenza et al., 2006), posterior cortical atrophy (e.g., Miller et al., 2018), acute vestibular neuritis (e.g., Moser, Vibert, Caversaccio \& Mast, 2017a), peripheral vestibular deficits (e.g., Moser et al., 2017b), developmental language disorder (e.g., Verly et al., 2018), or dyslexia (e.g., Koerte et al., 2016) were excluded. The study of Shalev et al. (1995) was included, although 13 out of the 25 dyscalculic children had a diagnosis of ADHD, but only the data from participants without the disorder were used. Rubinsten and Henik (2006) used both a group of participants with dyscalculia and a group with dyslexia in which case only the data of the former group were used. Similarly, when studies included groups of individuals with comorbidity or other disorders (e.g., reading deficiency or dual deficiency; Greiffenstein \& Baker, 2002), or groups of individuals with high scores in mathematics (e.g., Kovas et al., 2009; Whittington \& Richards, 1991) only the data on individuals with MLD were included in the meta-analyses. 
Handedness: Studies that either encouraged or discouraged right- or lefthanders participate or it was not clear from description of the methods whether participants were right-handed on purpose or by chance were excluded (e.g., GómezVelázquez et al., 2017; González-Garrido et al., 2018; Grabner et al., 2009; StanescuCosson et al., 2000; Strang \& Rourke, 1983). Those studies were excluded following a conservative approach. Furthermore, in the case of brain imaging studies, where participants are typically selected for right-handedness, unless this choice was directly reported, the authors of the original studies were contacted and after confirmation studies were excluded (Kucian et al., 2006; Kucian, Loenneker, Martin, \& von Aster, 2011b; Rotzer et al., 2008) or included (Price et al., 2007).

Publication language: Reports written in English and Greek were included. The only exception was the study of Jovanović et al. (2014), which the author kindly translated for us.

A few studies did include participants with MLD and also provided information about their handedness, but the arithmetic data were not useable (e.g., Ashkenazi et al., 2012; Ayyildiz et al., 2019; Cohen, Gliksman, \& Henik, 2019; Huber, Nuerk, Reips, \& Soltanlou, 2017; Mazzocco \& Thompson, 2005; Rosenberg, 1989; Salvador et al., 2019; Shalev, Manor, \& Gross-Tsur, 1997; Whittington \& Richards, 1991). In addition, case studies were not included (e.g., DeVisscher \& Noël, 2013; Hsieh et al.,2017; Iuculano \& Cohen Kadosh, 2014; Martins et al.,1999; von Aster, 2000). When two studies used the same sample of individuals we kept only one (e.g., Kucian et al., 2011a; Michels, O’Gorman, \& Kucian, 2018; Lafay, Macoir, \& St-Pierre, 2018; Lafay, St-Pierre, \& Macoir, 2017). The McCaskey (2018a) dataset included all the participants from the longitudinal study reported in McCaskey et al. (2018) and most of the participants of McCaskey, Von Aster, O' Gorman Tuura and 
Kucian (2017). The McCaskey (2018b) dataset included only the participants that were additionally measured for the magnitude study reported in McCaskey et al. (2017), ensuring no participants data were entered into the meta-analyses twice. Finally, in the Spellacy and Peter (1978) study, the two groups of participants with MLD were merged for the purposes of this analysis.

\subsubsection{Moderators}

The possible moderating effect of a number of variables previously employed in meta-analyses on handedness in individuals with special educational needs (i.e., ASD; Markou et al., 2017; deafness; Papadatou-Pastou \& Safar, 2016; intellectual disability; Papadatou-Pastou \& Tomprou, 2015) was examined in the second set of meta-analyses where heterogeneity was found to be significant. There were sufficient data (at least three data points per level of a categorical moderator variable) to include the following variables as potential moderators:

Year of publication. The year of publication was entered numerically for each study. Year of publication of each study has been previously used as a proxy for secular change (e.g., Markou et al., 2017; Ntolka \& Papadatou-Pastou, 2017; Papadatou et al., 2008).

Location of the study. Two groups were formed, studies that took place in Europe $(n=14)$ and studies that took place outside of Europe $(n=8)$. The countries included in the second group came from Asia (Israel) $(n=3)$, America $(n=4)$, and Australia $(n=1)$. The creation of the non-Europe group was deemed necessary because of the low number of studies in each of the included locations.

Sex ratio. Possible sex differences in the handedness prevalence in MLD could not be directly investigated, because no published study broke down the results by sex. The sex ratio of participants was therefore used and entered numerically as the 
percentage of female participants. It should be noted that one study did not report the sex distribution of its samples (Price et al., 2007) and could not be entered into the sex ratio analysis.

Mean age of $M L D$. The mean age of the participants was entered numerically as mean age in years in order to ensure consistency between the studies. When only the age range was available, we used the midpoint of the range (e.g., in Jastrzebski, Crewther, \& Crewther, 2015, the age range reported was 19-33 years and the midpoint used in our analysis was 26 years). Two studies did not report the age of their samples (Jovanović et al., 2014; Price et al., 2007) and could not be entered into the mean age analysis.

Age group (adults/children). Age was also employed as a categorical variable using the categories children or adults.

Classification of handedness. The classification of handedness in the studies that were included in the meta-analyses followed either a binary classification with two handedness classes (right- or left-handed; RH-LH; right- or non-right-handed; RH-nonRH; dextral or non-dextral; D-ND) or a classification with three handedness classes (right-, left-handed or ambidextrous; right-; strong left-, strong right-handers, or remainder). The studies were coded for classification of handedness using two different groupings: (a) studies with two handedness classes and (b) studies with three handedness classes.

Measurement of handedness -instrument. The studies were coded in two groups: a) studies that used the Edinburgh Handedness Inventory (Oldfield, 1971) and b) studies that used other instruments for measuring handedness or did not report on how handedness was measured. 
Measurement MLD -instrument. The studies were coded in two groups: a)

studies that used the ZAREKI-R and b) studies that used other forms of assessment.

Some further variables with a possible moderating effect were not examined due to missing or unusable data, namely the main purpose of the study, familial MLD, whether handedness was collected by self-report measures or observation, IQ, and the ethnicity of the participants. Only one study mentioned data about familial MLD (Shalev et al., 1995). In addition, only one of the studies indicated the report of handedness (i.e., self-report; Jovanovic et al., 2014). In the case of the ethnicity of the participants, only two studies reported it. In the first, the ethnicity of the final sample it included two more subgroups- was 51.1\% white/Caucasian, 21.3\% Hispanic, 6.4\% African American, 6.4\% Asian, 8.5\% other, and 6.4\% elected not to report (Skeide et al., 2018). In the second one, all participants were French-speaking and selected from French schools in Quebec City, Canada (Lafay et al., 2017).

\subsubsection{Statistical analysis}

Data analysis was performed using R Studio v.3 (R Core Team, 2018) using the packages robumeta and meta. Two separate meta-analysis sets were conducted following the steps listed below (following Markou et al., 2017; Papadatou-Pastou \& Safar, 2016; Papadatou-Pastou \& Tomprou, 2015):

Step 1. Effect size calculation. An effect size together with its $95 \%$ confidence interval was calculated for each data set independently. Two effect sizes were used: (a) for meta-analysis set 1 , the ratio of atypical handedness odds (OR) between individuals with MLD and TA individuals, and (b) for meta-analysis set 2 the handedness rate for individuals with MLD. In the case of the odds ratio, a value of 1.0 corresponds to the null hypothesis of no differences in handedness between individuals with MLD and TA individuals, whereas values greater than 1.0 indicate a 
larger proportion of atypical handedness among individuals with MLD.

Step 2. Heterogeneity tests and possible overall effect re-estimation using random effects. Three tests of homogeneity were used, namely the $Q$ statistic, the $\mathrm{Tau}^{2}$ statistic and the $I^{2}$ index. Of note, $I^{2}$ index levels of $25 \%, 50 \%$, and $75 \%$ are considered as low, moderate, and high, respectively (Higgins, Thompson, Deeks, \& Altman, 2003).

Step 3. Overall effect estimation using random effects. The overall effect was calculated as a weighted average of the effects sizes across all data sets. In the case of meta-analysis set 1 , the overall estimate can also be presented as a simple proportion using the formula $\mathrm{MLD}=\mathrm{TA} \times \mathrm{OR} /[1+\mathrm{TA}(\mathrm{OR}-1)]$, where $\mathrm{MLD}$ and TA are the probabilities of atypical handedness in individuals with MLD and TA populations, respectively. Simple proportions are easier to grasp intuitively, hence this transformation was also reported.

Step 4. Small study bias analysis. Small studies might be only published when reporting the desired effect, hence they might contribute to publication bias, which can distort the overall effect. The presence of small study bias was tested using the funnel plot graphical test and Egger's $t$ statistical test. Duval and Tweedie's (2000) trim and fill method of correcting bias was also used. Publication bias was only assessed in the first set of meta-analyses, on the odds ratio of handedness between MLD and TA, as in the second set of meta-analyses, the prevalence of handedness in MLD, the event rate (the effect size of interest) cannot be subject to publication bias (no comparisons are being made, hence no expected finding). Still, in the first set of meta-analyses, no published studies aimed specifically at investigating handedness odds between MLD and TA, thus publication bias is reported here with caution. 
Step 5. Moderator variables analysis. In the case of meta-analysis set 2, significant heterogeneity between studies was found to exist, making it necessary to search for the presence of moderators. Meta-regression using the method of moments was used in order to test for the moderating effect of the interval moderator variables (i.e., year of publication, sex ratio, and mean age), with evaluation in terms of the $\mathrm{I}^{2}$ statistic. In the case of categorical moderator variables (i.e., classification of handedness, location, measurement of handedness, measurement of MLD, and age group) the average effect sizes in the different subgroups that form the levels of the moderator were compared again by means of the $\mathrm{I}^{2}$ statistic.

Each set of meta-analyses included three different comparisons: (i) lefthandedness, (ii) non-right-handedness, and (iii) mixed-handedness. In the lefthandedness comparison, left-handers were either (i) the participants classified as lefthanders in the binary classifications (RH-LH, RH-nonRH, or D-ND) or (ii) the participants at the left extreme of three-way classifications (right-, left-handed or ambidextrous; strong left-, strong right-handers, or remainder). In the non-righthandedness comparison, non-right-handers were (i) the participants classified as lefthanders, non-right-handers, non-dextral in the studies using binary classifications as well as (ii) the participants that were classified as left-handers and as ambidextrous or remainder in studies employing three-way classifications. Forest plots were used as a graphical display of the findings.

\subsection{Results}

A total of 22 studies were included in the analyses adding up to $n=3,667$ participants ( $n=1,017$ individuals with MLD, $n=2,650$ TA individuals). The details of all studies used can be found in Table 7 . 


\subsubsection{Meta-analysis set 1: MLD-to-TA handedness odds ratios}

Overall effect estimate (left-handedness): This comparison included $k=13$ datasets adding up to $n=2,622$ individuals ( $n=741$ individuals with MLD, $n=1,881$

TD individuals). The studies of Price et al. (2007), Skeide et al. (2018), and McCaskey (2018b) had zero left-handers in both the MLD and the TA groups, which cannot be translated into a ratio. There was no evidence of heterogeneity among the data sets, $Q(12)=7.56, p=.80, \mathrm{Tau}^{2}=.00$, with no inconsistency between studies, $I^{2}=.00 \%$, indicating that no variables moderate the MLD-to-TA left-handedness odds ratio. A random effects model was employed, which gave a pooled odds ratio $(\mathrm{OR})=$ $1.06,95 \%$ confidence interval $(\mathrm{CI})=.79,1.42, Z=.42, p=.67$ (see Figure 3$)$. Therefore, there is no statistical evidence for differences between MLD and TA individuals in terms of left-handedness. The analysis was repeated after removing the largest study representing $68.1 \%$ of participants (Study 2, $n=1893$ ) and no evidence of a difference was similarly found $(\mathrm{OR}=1.59,95 \%$ confidence interval $(\mathrm{CI})=.95$, $2.68, Z=1.77, p=.07)$. We refrain from interpreting the last $p$-value as weak evidence for a difference, as three studies showing no differences but reporting zero left-handers for both groups were not included in the analysis, as mentioned above (McCaskey, 2018b; Price et al., 2007; Skeide et al., 2018). Egger's $t$ provided evidence for small study bias, $t(11),=3.44, p=.006$. Visual inspection of the funnel plot graphical test marginally suggests that the left side of the funnel (representing lower odds of non-right-handedness for the MLD individuals) might be slightly underrepresented (see Figure 3). Using Duval and Tweedie's trim and fill method for bias correction for the fixed effects model six datasets were "filled" to the left of 
mean, representing no differences between MLD and TA individuals, and the adjusted overall estimate was $.97,95 \%$ CI .73, 1.28 .

a)

\begin{tabular}{|c|c|c|c|c|}
\hline Study & Events & $\begin{array}{l}\text { MLD } \\
\text { Total }\end{array}$ & Events & $\begin{array}{r}\text { TD } \\
\text { Total }\end{array}$ \\
\hline Rubinsten \& Henik (2006) & 2 & 17 & 3 & 17 \\
\hline Study 2 & 43 & 445 & 157 & 1448 \\
\hline Ashkenazi \& Henik (2010) & 4 & 12 & 4 & 12 \\
\hline Lafay et al. (2017) & 5 & 24 & 6 & 31 \\
\hline Jovanovic et al. (2014) & 7 & 83 & 4 & 57 \\
\hline Jastrzebski et al. (2015) & 1 & 5 & 2 & 14 \\
\hline Study 1 & 7 & 45 & 8 & 89 \\
\hline McCaskey 1 (unpublished 2018) & 3 & 22 & 1 & 13 \\
\hline Kucian (unpublished 2018) & 3 & 28 & 1 & 24 \\
\hline Study 3 & 2 & 19 & 3 & 134 \\
\hline Kucian et al. (2011) & 1 & 16 & 0 & 16 \\
\hline Kucian et al. (2014) & 1 & 15 & 0 & 15 \\
\hline Rotzer et al. (2009) & 1 & 10 & 0 & 11 \\
\hline Random effects model & & 741 & & 1881 \\
\hline
\end{tabular}

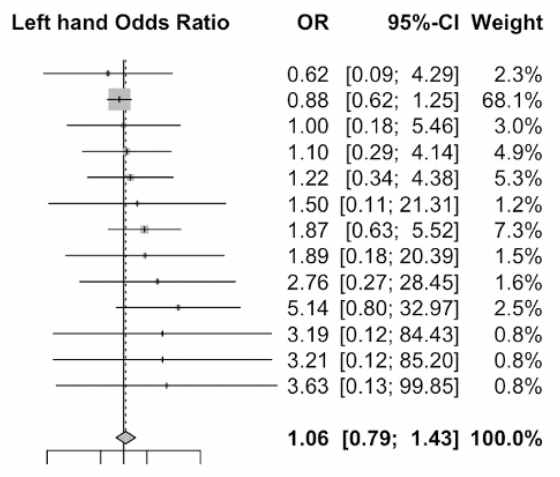

b)

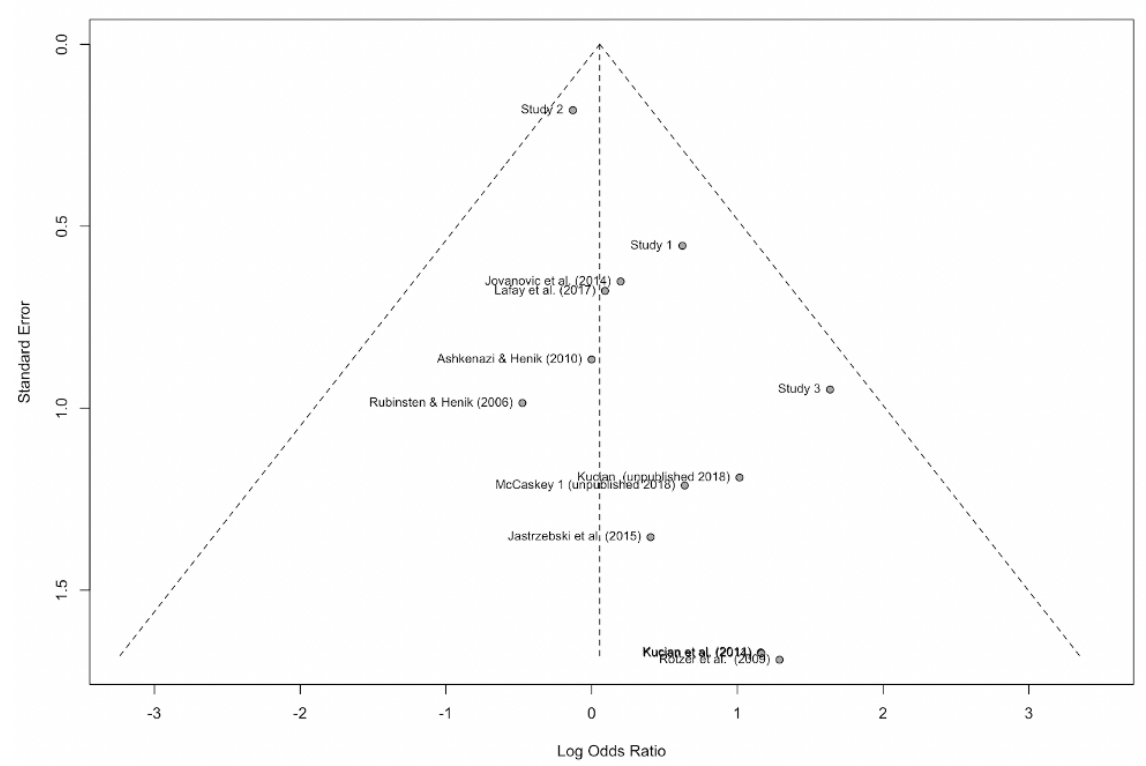

Figure 3. a) Forest plot for the left-handedness comparison. In the plot the $95 \%$ confidence interval for each study is represented by a horizontal line and the point estimate is represented by a vertical line. The confidence intervals for totals are represented by a diamond shape at the bottom of the plot. b) Funnel plot of standard error on log odds ratio, for the left-handedness comparison. 
Overall effect estimate (non-right-handedness): This comparison included $k=$ 14 studies adding up to $n=2,646$ individuals $(n=747$ individuals with MLD, $n=$ 1899 TD individuals). Price et al. (2007) and Skeide et al. (2018) reported zero nonright-handers for both MLD and TA individuals and were not included. There was no evidence of heterogeneity among the datasets, $Q(13)=10.59, p=.65, \mathrm{Tau}^{2}=.00$, with no inconsistency between studies, $I^{2}=.00 \%$, indicating that no variables moderate the MLD-to-TA non-right-handedness odds ratio. A random effects model was employed, which gave a pooled odds ratio $(\mathrm{OR})=1.04,95 \%$ confidence interval $(C I)=.79,1.37, Z=.31, p=.75$ (see Figure 4). Therefore, there is no statistical evidence for differences between MLD and TA individuals in terms of non-righthandedness. The analysis was repeated after removing the largest study representing $64.4 \%$ of participants (Study 2, $n=1907$ ) and no evidence of a difference was similarly found $(\mathrm{OR}=1.42,95 \%$ confidence interval $(\mathrm{CI})=.89,2.260, Z=1.45, p=$ .13). Egger's $t$ showed no evidence of small study bias, $t(12),=2.07, p=.06$. However, visual inspection of the funnel plot graphical test marginally suggests that the left side of the funnel (representing lower odds of non-right-handedness for the MLD individuals) might be slightly underrepresented (see Figure 6). Using Duval and Tweedie's trim and fill method for bias correction for the fixed effects model three datasets were "filled" to the left of mean, representing no differences between MLD and TD individuals, and the adjusted overall estimate was .94, 95\% CI .72, 1.23. 
a)

\begin{tabular}{|c|c|c|c|c|c|c|c|c|c|}
\hline Study & Events & $\begin{array}{l}\text { MLD } \\
\text { Total }\end{array}$ & Events & $\begin{array}{r}\text { TD } \\
\text { Total }\end{array}$ & Non right hand & d Odds Ratio & OR & $95 \%-\mathrm{Cl}$ & Weight \\
\hline McCaskey 2 (unpublished 2018) & 0 & 3 & 1 & 7 & & & 0.62 & {$[0.02 ; 19.58]$} & $0.6 \%$ \\
\hline Kucian et al. (2011) & 2 & 16 & 4 & 16 & & — & 0.43 & {$[0.07 ; 2.76]$} & $2.2 \%$ \\
\hline Rubinsten \& Henik (2006) & 2 & 17 & 3 & 17 & & & 0.62 & {$[0.09 ; 4.29]$} & $2.1 \%$ \\
\hline McCaskey 1 (unpublished 2018) & 9 & 22 & 6 & 13 & & & 0.81 & {$[0.20 ; 3.22]$} & $4.0 \%$ \\
\hline Study 2 & 46 & 448 & 168 & 1459 & $\frac{1}{1}$ & & 0.88 & {$[0.62 ; 1.24]$} & $64.4 \%$ \\
\hline Ashkenazi \& Henik (2010) & 4 & 12 & 4 & 12 & & & 1.00 & {$[0.18 ; 5.46]$} & $2.7 \%$ \\
\hline Lafay et al. (2017) & 5 & 24 & 6 & 31 & & & 1.10 & {$[0.29 ; 4.14]$} & $4.3 \%$ \\
\hline Jovanovic et al. (2014) & 7 & 83 & 4 & 57 & & & 1.22 & {$[0.34 ; 4.38]$} & $4.7 \%$ \\
\hline Study 1 & 7 & 45 & 8 & 89 & - & $\rightarrow$ & 1.87 & {$[0.63 ; 5.52]$} & $6.5 \%$ \\
\hline Kucian (unpublished 2018) & 3 & 28 & 1 & 24 & & & 2.76 & {$[0.27 ; 28.45]$} & $1.4 \%$ \\
\hline Kucian et al. (2014) & 3 & 15 & 1 & 15 & & & 3.50 & {$[0.32 ; 38.23]$} & $1.3 \%$ \\
\hline Study 3 & 2 & 19 & 4 & 134 & & & 3.82 & {$[0.65 ; 22.47]$} & $2.4 \%$ \\
\hline Jastrzebski et al. (2015) & 2 & 5 & 2 & 14 & & & 4.00 & {$[0.39 ; 41.23]$} & $1.4 \%$ \\
\hline Rotzer et al. (2009) & 5 & 10 & 2 & 11 & - & & 4.50 & {$[0.63 ; 32.29]$} & $2.0 \%$ \\
\hline \multirow{2}{*}{\multicolumn{2}{|c|}{$\begin{array}{l}\text { Random effects model } \\
\text { Heterogeneity: } I^{2}=0 \%[0 \% ; 45 \%], \tau^{2}=0, \chi_{13}^{2}\end{array}$}} & \multirow[t]{2}{*}{747} & \multirow{2}{*}{\multicolumn{2}{|c|}{1899}} & & & \multirow{2}{*}{\multicolumn{2}{|c|}{$1.04[0.79 ; 1.38]$}} & $100.0 \%$ \\
\hline & & & & & & & & & \\
\hline
\end{tabular}

b)

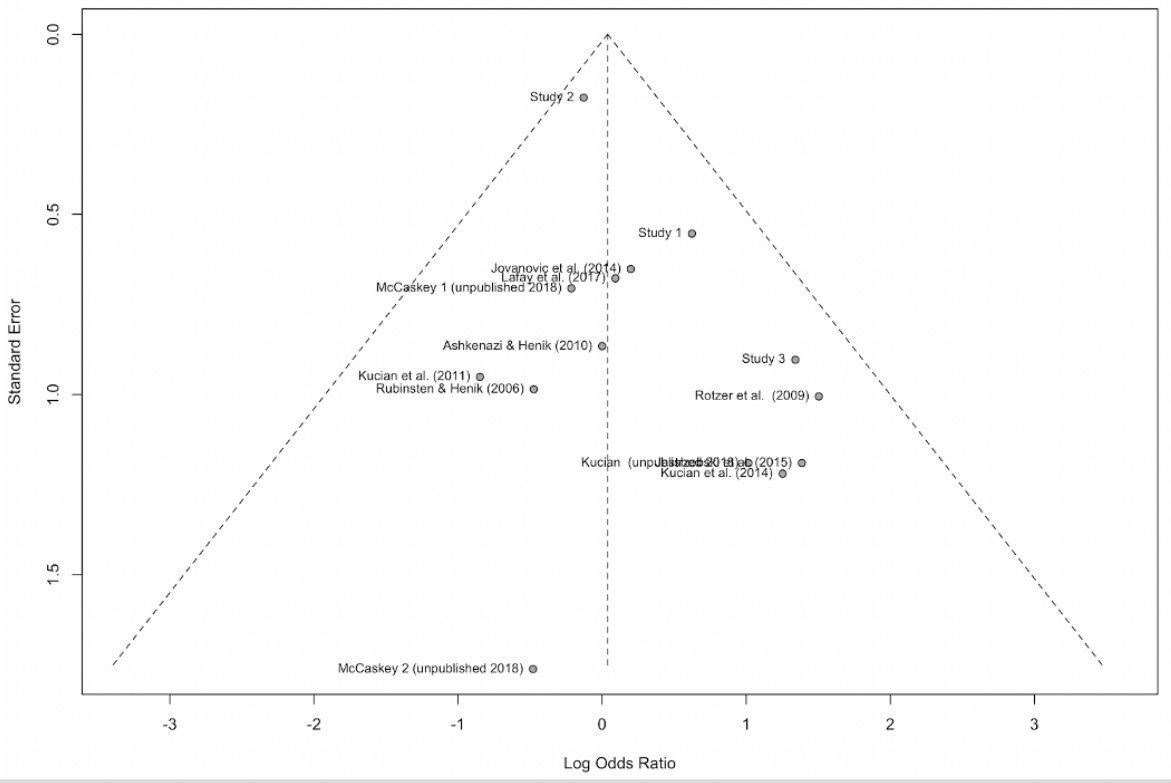

Figure 4. a) Forest plot of the non-right-handedness comparison. b) Funnel plot of standard error on log odds ratio, for the non-right-handedness comparison.

Overall effect estimate (mixed-handedness): This comparison included $k=9$ studies adding up to $n=2,372$ individuals ( $n=603$ individuals with MLD, $n=1,769$ TD individuals). The studies of Ashkenazi and Henik (2010), Jovanović et al. (2014), Price et al. (2007), and Rubinsten and Henik (2006) could not be included, as they reported zero mixed-handers for both MLD and TA individuals, which cannot be translated into a ratio. There was no evidence of heterogeneity among the datasets, $Q(8)=5.82, p=.66$, Tau $^{2}=.00$, with no inconsistency between studies, $I^{2}=.00 \%$, indicating that no variables moderate the MLD-to-TA mixed-handedness odds ratio. 
A random effects model was employed, which gave a pooled odds ratio $(\mathrm{OR})=1.2$, $95 \%$ confidence interval $(\mathrm{CI})=.67,2.174, Z=.63, p=.52$ (see Figure 6 ). Therefore, there is no statistical evidence of differences between MLD and TA individuals in terms of mixed-handedness. The analysis was repeated after removing the largest study representing $79.62 \%$ of participants (Study $2, n=1905$ ) and no evidence of a difference was similarly found $(\mathrm{OR}=1.241,95 \%$ confidence interval $(\mathrm{CI})=.66,2.35$, $Z=.68, p=.49)$. Egger's $t$ showed no evidence of small study bias, $t(7), \mathrm{t}=.05, p=$ .93. Visual inspection of the funnel plot graphical test did not suggest any asymmetries (see Figure 5), but using Duval and Tweedie's trim and fill method for bias correction for the fixed effects model one dataset was "filled" to the left of mean, representing no differences between MLD and TD individuals, and the adjusted 
overall estimate was $1.21,95 \%$ CI .68, 2.18 .

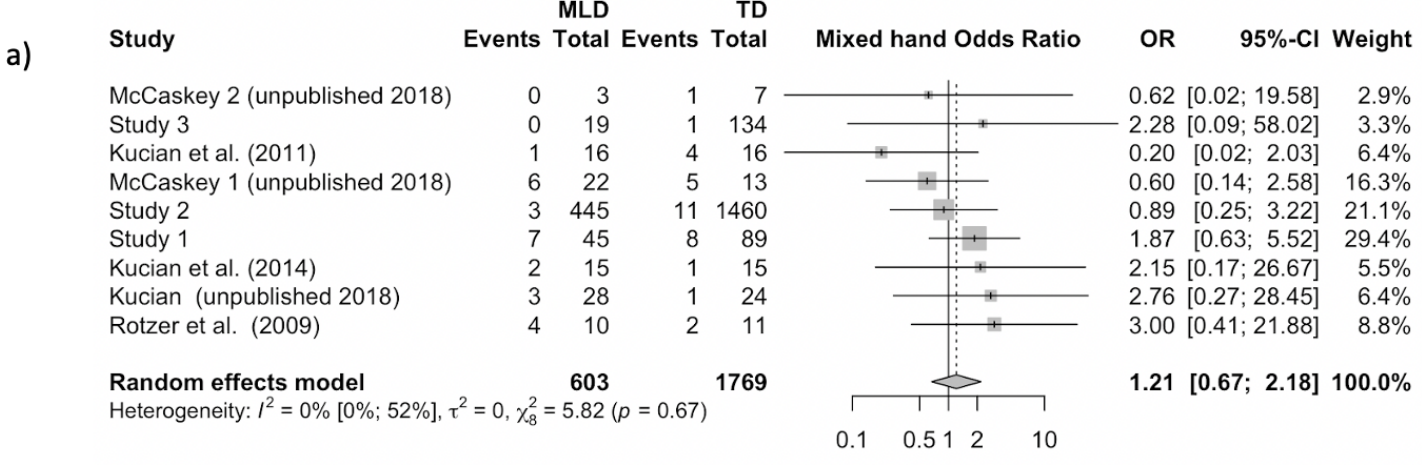

b)

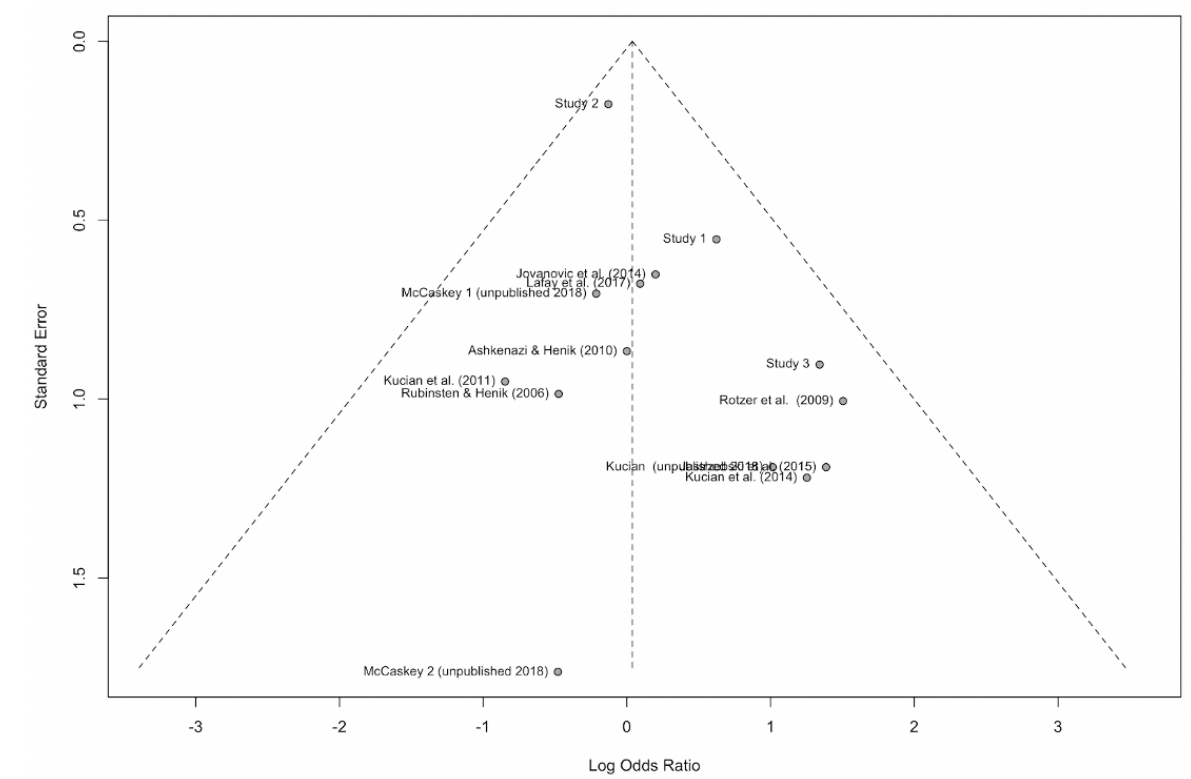

Figure 5. a) Forest plot of the mixed-handedness comparison. b) Funnel plot of standard error on log odds ratio, for the mixed-handedness comparison.

\subsubsection{Meta-analysis set 2: Handedness prevalence in individuals with MLD}

Overall effect estimate (left-handedness). A total of $k=22$ data sets were included in the analysis, totaling $n=1,017$ individuals with MLD. There was evidence of moderate-to-high heterogeneity among studies, $I^{2}=67.8 \%, Q(21)=65.8$, $p<.001, \mathrm{Tau}^{2}=.49$, indicating the presence of moderator variables. A random effects model was employed, which gave a weighted average of left-handedness prevalence across all data sets of $19.8 . \%, 95 \%$ confidence interval $(\mathrm{CI})=12.8 \%, 26.9 \%, p<$ 
.001) (see Figure 6). In other words, the range of the left-handedness prevalence in the distribution of populations studied is $12.8 \%$ to $26.9 \%$. Egger's t showed no evidence of small study bias, $t(20), \mathrm{t}=.8647, \mathrm{p}=.3975$.

\section{Left hand prevalence}

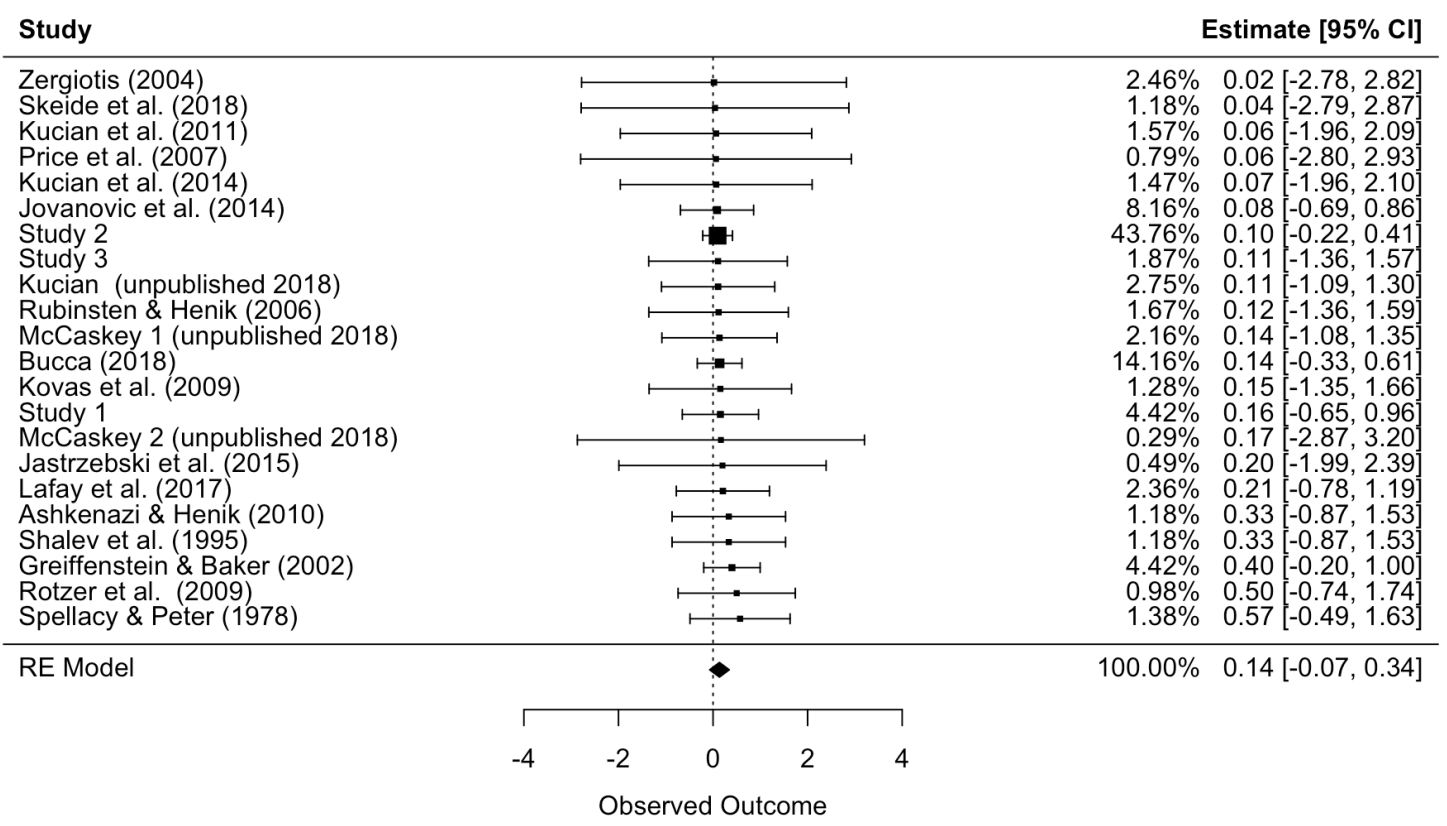

Figure 6. Forest plot for the left-handedness event rate. Estimate effects sizes are estimated as the logit of event rates.

Overall effect estimate (non-right-handedness). A total of $k=22$ data sets were included in the analysis, totaling $n=1,020$ individuals with MLD. There was evidence of high heterogeneity among the datasets, $I^{2}=66.9 \%, Q(21)=69.5, p<$ $.001, \mathrm{Tau}^{2}=.41$, indicating the presence of moderator variables. A random effects model was employed, which gave a weighted average of non-right-handedness prevalence across all data sets of $23.4 \%$ with a $95 \%$ confidence interval $(\mathrm{CI})=16.7 \%$, $30.1 \%,, p<.001$ (see Figure 7). In other words, the range of the non-right-handedness prevalence in the distribution of populations studied is $16.7 \%$ to $30.1 \%$. Egger's $\mathrm{t}$ showed no evidence of small study bias, $\mathrm{t}(20), \mathrm{t}=1.6026, p=.1247$ 
Skeide et al. (2018)

Price et al. (2007)

Jovanovic et al. (2014)

Study 2

Rubinsten \& Henik (2006)

Kucian et al. (2011)

Bucca (2018)

Kovas et al. (2009)

Zergiotis (2004)

McCaskey 2 (unpublished 2018)

Study 1

Kucian (unpublished 2018)

Kucian et al. (2014)

Lafay et al. (2017)

Ashkenazi \& Henik (2010)

Shalev et al. (1995)

Greiffenstein \& Baker (2002)

Jastrzebski et al. (2015)

McCaskey 1 (unpublished 2018)

Rotzer et al. (2009)

Spellacy \& Peter (1978)

RE Model

Estimate $[95 \% \mathrm{Cl}]$

$1.18 \% \quad 0.04[-2.79,2.87]$

$0.78 \% 0.06[-2.80,2.93]$

$8.14 \% 0.08[-0.69,0.86$

$43.92 \% 0.10[-0.20,0.41]$

$1.86 \% 0.11[-1.36,1.57$

$1.57 \% \quad 0.12[-1.36,1.61]$

$14.12 \% \quad 0.14[-0.33,0.61]$

$1.27 \% 0.15[-1.35,1.66]$

$2.27 \% 0.15[-1.35,1.66$

$2.45 \% 0.16[-0.91,1.23]$

$\begin{array}{ll}0.29 \% & 0.17 \\ 4.41 \% & 0.18[-0.87,3.20 \\ 2.75 \% & 0.18[-0.79,1.94\end{array}$

$\begin{array}{ll}4.41 \% & 0.18[-0.59,0.94] \\ 2.75 \% & 0.18[-0.79,1.15]\end{array}$

$1.47 \% \quad 0.20[-1.07,1.47$

$2.35 \% \quad 0.21-0.78,1.19$

$1.18 \% \quad 0.33-0.87,1.53$

$1.18 \% \quad 0.33[-0.87,1.53]$

$4.41 \% \quad 0.40[-0.20,1.00]$

$0.49 \% \quad 0.40[-1.39,2.19]$

$2.16 \% \quad 0.41[-0.44,1.26]$

$0.98 \% \quad 0.50[-0.74,1.74]$

\begin{tabular}{rr}
$1.37 \%$ & $0.57[-0.49,1.63]$ \\
\hline $00.00 \%$ & $0.15[-0.03,0.34]$
\end{tabular}

$-4$

Observed Outcome

Figure 7. Forest plot for the non-right-handedness event rate. Estimate effects sizes

are estimated as the logit of event rates

Overall effect estimate (mixed-handedness). A total of $k=11$ data sets were

included in the analysis, totaling $n=711$ individuals with MLD. There was evidence

of high heterogeneity among the datasets, $I^{2}=77.96 \%, Q(10)=46.24, p<.001$, $\mathrm{Tau}^{2}$

$=1.68$, indicating the presence of moderator variables. A random effects model was

employed, which gave a weighted average of mixed-handedness prevalence across all

data sets of $15 \%$ with a $95 \%$ confidence interval $(\mathrm{CI})=6.2 \%, 23.8 \%, p=.003$ (see

Figure 8). In other words, the range of the mixed-handedness prevalence in the

distribution of populations studied is $6.23 \%$ to $23.8 \%$. Egger's t showed no evidence

of small study bias, $\mathrm{t}(9), \mathrm{t}=-.9398, p=.3719$ 
Mixed hand prevalence

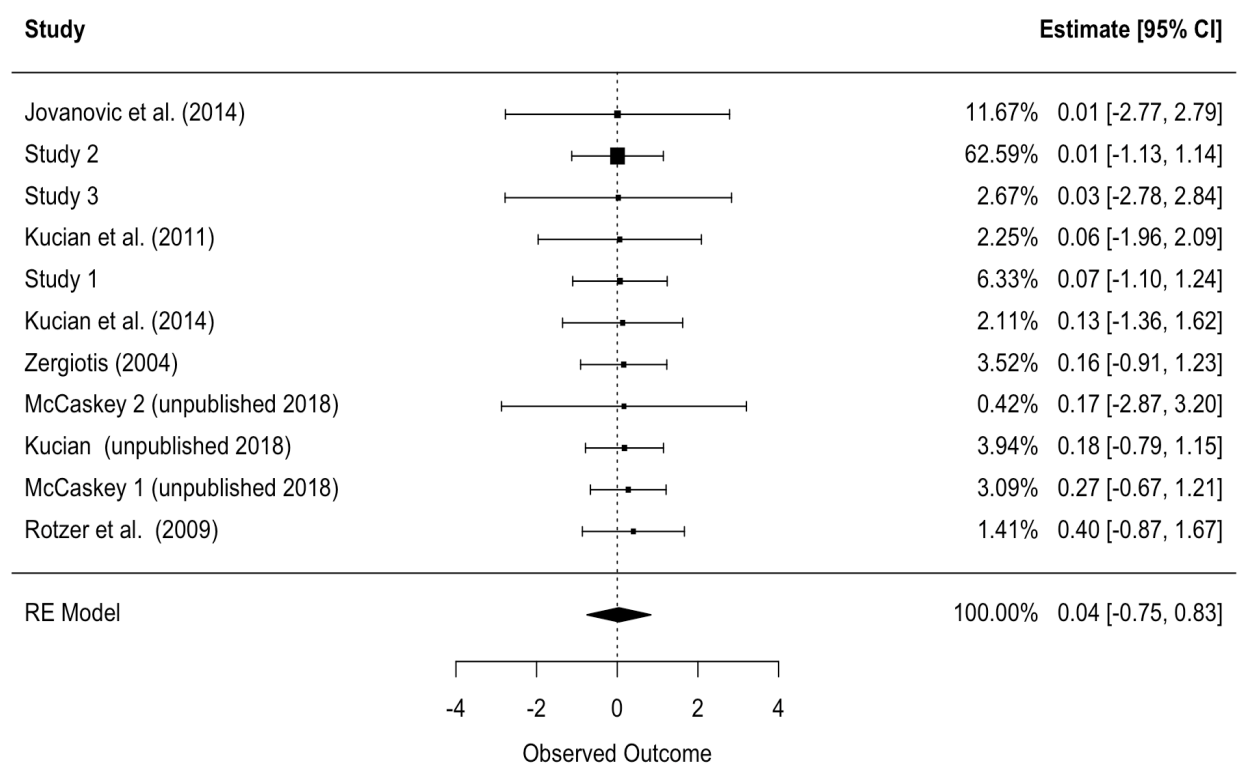

Figure 8. Forest plot for the mixed-handedness event rate. Estimate effects sizes are estimated as the logit of event rates.

Moderating variables analysis. Because of the heterogeneity detected among studies in meta-analysis set 2 , the moderating effects of the previously indicated variables were tested within the left-handedness and the non-right-handedness comparisons. The mixed-handedness comparisons did not include enough data sets to allow for moderating variables analysis. Below the results of the left-handedness comparison are presented. Only when the non-right-handedness comparison gave different statistical evidence are the results for this comparison reported.

Publication year. The three new studies reported in the present paper were included using 2019 as the year of publication. Meta-regression of the year of publication of the studies revealed clear evidence of a linear trend in left-handedness (I2 $=62.8 \%, p$ $<.001)$. The best-fitting linear relation between log event rate and year being $\ln ($ event rate $)=-.06719$ (year $)+133.42$, reflecting an decrease in the estimated rate of left-handedness in MLD individuals between 1978 and 2019. 
Location of the study. Location was found to have a clear moderating effect on lefthandedness prevalence, $\mathrm{I} 2=76.60 \%, p=.01$. The best-fitting linear relation between logit event rate and year being $\ln ($ event rate $)=1.35$ (location $)+-2.05$. It was found that individuals with MLD have a left-handedness prevalence of $14.2 \%$ (95\% CI $7.49 \%, 20.9 \%)$ and of $29.8 \%(95 \% \mathrm{CI}, 16.2 \%, 42.3 \%)$ when residing in a country in Europe (14 studies) and in a non-European country (America, Asia, Australia; 8 studies), respectively. Small levels of heterogeneity were found both within studies conducted in Europe, $\mathrm{p}<.01, \mathrm{I} 2=69.04 \%$, and small to moderate heterogeneity within studies performed in non-European countries, , $\mathrm{p}<.01, \mathrm{I} 2=83.90 \%$. Sex ratio. Meta-regression was performed and it was found that the percentage of females in the study sample did not affect the pooled effect estimate of the metaanalysis $\mathrm{I} 2=0 \%, p=.22$.

Mean age. Meta-regression of the mean age did not provide evidence as to whether mean age moderates left-handedness rates in $\operatorname{MLD}(p=.21)$. . In the case of nonright-handedness there was only weak evidence of a moderating effect of mean age, $p$ $=.08, \mathrm{I} 2=88.41 \%$. Age group (children/adults). The prevalence of left-handedness was found to be $18.5 \%$ (95\% CI, $10.2 \%, 26.9 \%)$ and $27.9 \%$ (95\% CI, 6.58\%, 49.3\%)in children (18 studies) and adults (4 studies), respectively. No evidence for a moderating effect of age group was found, $p=.18$. Heterogeneity was further examined within the two age groups, which revealed moderate to high heterogeneity within studies that used children as participants, $\mathrm{I} 2=86.61 \%$, as well as within studies that used adult participants, $\mathrm{I} 2=78.71 \%$. Of note, the fact that only four studies had adult samples, calls for caution when interpreting this comparison. 
Classification of handedness. The prevalence of left-handedness was found to be $27.7 \%(95 \% \mathrm{CI}, 16 \%, 39.5 \%)$ and $14 \%(95 \% \mathrm{CI}, 5.42 \%, 22.6 \%))$ in two-way $(9$ studies) and three-way (12 studies) classifications, respectively. There was clear evidence of a moderating effect of classification, $p=.04$. Heterogeneity was further examined within the two classifications, which revealed high heterogeneity within two-way classification, $\mathrm{I} 2=91.04 \%$, and moderate to high heterogeneity within the three-way classification, $\mathrm{I} 2=73.39 \%$, In the case of non-right-handedness this analysis was not applicable.

Measurement of handedness -instrument. The prevalence of left-handedness was found to be $17.5 \%(95 \% \mathrm{CI}, 2.41 \%, 32.7 \%)$ when handedness was assessed with the Edinburgh Handedness Inventory (7 studies) and 20.6\% (95\% CI, 11.8\%, 29.5\% ) when handedness was measured with another instrument, or no instrument was reported (15 studies). No evidence for a moderating effect of the instrument was found, $p=.93$. Heterogeneity was further examined and revealed high heterogeneity within the studies that used other instruments than the Edinburgh Handedness Inventory, $I^{2}=81.38 \%$, and high heterogeneity within the studies that had used the Edinburgh Handedness Inventory, $I^{2}=90.99 \%$.

Measurement of MLD -instrument. The prevalence of left-handedness was found to be $18.7 \%(95 \% \mathrm{CI}, 3.57 \%, 33.8 \%)$ when mathematical ability was assessed with the Zareki-R (7 studies) and 20.2\% (95\% CI, 11.3\%, 29.2\%) when mathematical ability was measured with another instrument or no instrument was reported. No evidence of a moderating effect of the instrument was found $p=.62$. Heterogeneity was further examined and revealed high heterogeneity within the studies that used other instruments than the Zareki-R, $I^{2}=79.51 \%$, and high to moderate heterogeneity within the studies that had used the Zareki-R, $Q(6)=9.72, p=.14, I^{2}=91.12 \%$. 
HAND PREFERENCE AND MLD

\subsection{Discussion}

Within Study 4, two separate sets of meta-analyses were carried out, including 22 studies that evaluated the handedness prevalence of 3,667 participants, of whom 1,017 were diagnosed with MLD and 2,650 were TA individuals. The first set of meta-analyses included studies that assessed handedness in both MLD and TA. The second set of meta-analyses included studies that reported the handedness prevalence of individuals with MLD irrespective of the presence of a control group.

Meta-analysis set 1 failed to find any statistical evidence for a difference in atypical handedness odds between individuals with MLD and TA individuals for all three comparisons (left-, non-right-, and mixed-handedness). No heterogeneity was further found within any of the three comparisons. Significant small study bias was detected only for the left-handedness comparison using Egger's test. However, for all three comparisons the Duval and Tweedie's trim and fill method identified studies missing from the left side of the plot indicating less atypical handedness in MLD compared to TD individuals.

According to meta-analysis set 2 , the left-handers prevalence rate among individuals with MLD ranges from $12.8 \%$ to $26.9 \%$, the prevalence rate of non-righthandedness from $16.7 \%$ to $30.1 \%$, and the prevalence rate of mixed handedness from $6.2 \%$ to $23.8 \%$, with the best point estimates being $19.8 \%, 23.4 \%$, and $15 \%$, respectively. These ranges are quite large and when it comes to left-handedness they do not include the $10.6 \%(95 \% \mathrm{CI} 9.71 \%, 11.50 \%)$ estimate of the left-handedness prevalence in the general population that was calculated by a recent large-scale metaanalysis (Papadatou-Pastou et al., 2020). Similarly, the non-right and mixedhandedness estimates are higher than those estimated for the general population by Papadatou-Pastou et al. (2020) (non-right-handedness: 18.10\%, 95\% CI [13.9\%, 
$22.30 \%$, mixed-handedness: $9.33 \%, 95 \%$ CI $[6.67 \%, 12.00 \%]$, but they do overlap in these cases.Therefore, meta-analysis set 2 does provide some evidence of elevated levels of atypical handedness in individuals with MLD, but the absence of a control group remains a limitation of this analysis.

Heterogeneity was found to be significant within all three comparisons of meta-analysis set 2 (left-, non-right, and mixed-handedness), indicating the presence of moderating variables. Therefore, the possible moderating effect of year of publication, location of the study, sex ratio, mean age, age group (adults vs. children), classification of handedness, instrument used measure handedness, and instrument used to diagnose MLD was investigated within the left- and non-right-handedness comparisons (the mixed-handedness comparison did not include enough studies for such a comparison to take place). For the year of publication, the location of the study, and the classification of handedness there was statistical evidence of a moderating effect on the prevalence of left-handedness among MLD individuals, with older studies, studies located in non-European countries, and studies using the right vs. left classification reporting a higher prevalence of left-handedness. The non-EU group consisted of only eight studies in countries with predominantly Caucasian populations, which should in theory be comparable with the EU samples. Thus, interpretation of this finding should be done with caution.

None of the other variables were found to exert a moderating effect on the handedness prevalence in MLD. This could be taken as indicating true absence of a moderating effect or due to the lack of sufficient data. Some studies did not report information on all the moderating variables, resulting in fewer studies included in the moderator variables analysis compared to the overall effect analysis. Another reason could be the low power of meta-analysis when it comes to detecting moderating 
effects (Hunter \& Schmidt, 1990). It is indeed the case that only large moderating effects can be detected within a meta-analysis, as the number of studies included and not the number of participants is what determines the power to detect such effects.

Limitations of the present study include the fact that all studies measured hand preference, with no information being given on hand skill. Hand skill is an important parameter for the evaluation of the function of central nervous system (Gundogan, Kiziltan, Aydin, \& Ogus, 2016). Moreover, all studies treated handedness as a categorical variable, with only one study providing information on the degree of handedness (McCaskey, 2018a; McCaskey, 2018b). Degree of handedness may be a more appropriate indicator of cerebral organization and of behavior than direction of handedness (Prichard, Propper, \& Christman, 2013). Prichard et al. (2013) argue that previous research has failed to identify individual differences in handedness effects on behavior as direction of handedness was used as the handedness criterion, therefore differences associated with degree could not be detected. The distinction between direction and degree of handedness is further important for the reason that functional magnetic imaging studies have shown that these two aspects are independent and encoded separately in the brain (Dassonville et al., 1997). Had hand skill and degree of handedness data been included in the present meta-analyses, it could be the case that the findings would have been different. Another limitation is that only a handful of studies tested adult participants (Ashkenazi \& Henik, 2010; Greiffenstein \& Baker, 2002; Jastrzebski et al., 2015; Rubinsten \& Henik, 2006), with their average age not exceeding thirty years. Thus, further developmental effects could not have been investigated. Moreover, not all variables with a possible moderating effect were examined due to missing or unusable data, namely the main purpose of the study, familial MLD, whether handedness was 
collected by self-report measures or not, participants' IQ, and the ethnicity of the participants. When conducting Study 4, we could not use the continuous score of mathematical performance of the participants as a moderator variable, as only the seven studies using the Zareki test reported such scores (Kucian et al., 2011a; Kucian et al., 2014; Kucian, unpublished 2018; Lafay et al., 2017; McCaskey 1, unpublished 2018; McCaskey 2, unpublished 2018; Rotzer et al., 2009). Only McCaskey (2018b) used an adolescent sample, therefore this could not be used as a separate age category and was not included in the age category analysis.

\section{Overall Discussion}

The present study investigated atypical handedness (i.e., left-, non-right-, and mixed-handedness) in individuals with MLD and reports both new data from three different countries, as well as two sets of meta-analyses. Despite evidence in the published literature of elevated levels of atypical handedness in general population samples with low mathematical abilities (e.g., Johnston et al., 2013) and in individuals with neurodevelopmental disorders (e.g., Markou et al., 2017), this is the first study to specifically investigate the relationship between handedness and MLD.

Study 1 did not find evidence of a difference in atypical handedness between MLD and TA individuals, when handedness direction was taken under consideration (i.e., when comparing left- and right-handers), except for weak evidence of a difference when only writing hand was used as the handedness criterion (merging those that used their left hand with those who reported using both hands, $p=.049$ ). Of note, Papadatou-Pastou, Martin, and Munafò (2013), using a sample balanced for handedness and sex, found that the mismatch in classifying participants into handedness groups between writing and hand preference inventories was $.4 \%$ for right-handers, but $13.5 \%$ for left-handers. Study 1 further showed that hand 
preference scores were correlated with mathematical achievement scores $(p<.001)$, which was stronger in the MLD group $(p=.001)$ than the TA group $(p=.04)$. Study 2, which used writing hand as the handedness criterion, similarly found no evidence of a difference in left-handedness between MLD and TA individuals. Study 3 further found no differences between MLD and TA individuals neither when direction of hand preference was employed, nor when degree of hand skill task was employed.

These findings point to the direction of no relationship between handedness and MLD, even if Study 1 provides some weak evidence of such a relationship. This picture is representative of the handedness literature, where different studies, especially if they measure and operationalize handedness using different measures and classifications, provide different findings. In a recent meta-analysis on the prevalence of handedness Papadatou-Pastou et al. (2020) urge researchers to define universal criteria for measuring hand preference, a message we would like to reinforce here. Specifically, we ask for short questionnaires, the reporting both writing hand and Edinburgh Handedness Inventory scores, and the reporting of at least two classifications, for example R-L and R-M-L, as well as making raw data publically available in open-access repositories. It is moreover suggested that future studies include information on hand skill and degree of handedness. Additionally, the data should be broken down by age and gender, in order for those relationships to be investigated as well. Publishing registered reports before embarking on data collection is also recommended, as this practice can act as a safeguard against publication bias as well as against a host of other replication-related issues, such as $p$ hacking. It is encouraging that such efforts are already taking place within the field of handedness (e.g., Pritchard, Malone, Burgoyne, Burgoyne, Heron-Delaney, \& Bishop, 2019). In addition to these good practices, the literature would also benefit from a 
clear and consistent definition of MLD, leading to a better identification of individuals who present with them and a better matching of control individuals.

When combining the evidence of the three studies reported here for the first time with already published data, no evidence of a difference in the odds ratio of atypical handedness between MLD and TA participants was found (all $p<.05)$. When synthesizing the data of studies that measured handedness in MLD without the presence of a control group, then the observed levels of atypical handedness were elevated compared to general population estimates (Papadatou-Pastou et al., 2020). However, the very absence of a control group does not allow for this evidence to be reliable, as the elevated levels of atypical handedness found could be due to a number of factors. For example studies might have implicitly recruited more individuals of atypical handedness or might have used more lax criteria for defining handedness groups. Of note, in the first set of meta-analyses, which used the odds ratio as the effect size, the base rate of atypical handedness of each study could not affect the estimated ratio between MLD and TA participants.

Overall, the evidence weights to the direction of atypical handedness levels not being different between MLD and TA individuals, at least when direction of hand preference is taken into account. Our findings challenge the link between handedness and mathematical ability supported by studies measuring low mathematical abilities in general population samples (e.g., Johnston et al., 2009).

The meta-analyses are limited by the fact that they included studies that measured only hand preference and not hand skill, the other manifestation of handedness. Moreover, primary studies grouped participants according to the direction of the participants' preference, hence no data on the degree of handedness was included in the meta-analysis. Of note, we were not able to exclude preterm 
individuals, as it has been shown that preterm birth is associated with higher levels of non-right handedness (Domellöf, Johansson, \& Rönnqvist, 2011).

Higher prevalence rates of atypical hand preference have been found in populations with other special education needs, such as dyslexia (Vlachos et al., 2013), deafness (Papadatou-Pastou \& Sáfár, 2016), and the low functioning end of the autism spectrum disorder (Markou et al., 2017). Dyslexia, deafness, and autism are conditions associated with poor outcomes on language-related abilities. When it comes to deafness, Papadatou-Pastou and Sáfár (2016) suggest that elevated levels of atypical handedness are found only in those deaf individuals who acquired language, be it either sign language or spoken language, at a later age. It is therefore here argued that elevated levels of atypical handedness are not a general characteristic of individuals with special educational needs, but rather specifically related to those conditions that affect language. Of note, no hand preference differences were found between children who stutter and children who do not stutter (Mohamadi \& Papadatou-Pastou, 2019), but stuttering is not a condition that affects language at a cognitive level, rather than articulation. Another possible explanation is that the handedness effect on MLD was too subtle to be detected in the present sample, given that some of the included studies had small sample sizes and that heterogeneity was detected in the second set of meta-analyses (albeit not in the first set). Moreover, direction of hand preference might not be a sensitive enough measure of handedness and other handedness measures, such as hand skill or degree of hand preference, might be more appropriate. Nicholls, Chapman, Loetscher, and Grimshaw (2010) similarly argue that when it comes to the effects of handedness on cognitive ability these are subtle and identifiable in large scale studies with sensitive measures of hand performance. 
In summary, we here report new data from three countries (Studies 1-3) and two sets of meta-analyses on the question of handedness in MLD (Study 4). The evidence points to the direction of no differences in atypical handedness levels in individuals with MLD compared to TA individuals, at least when the direction of hand preference is used as the handedness measure. We argue that the increased rates of atypical handedness that have been reported in recent meta-analyses on the relationship of handedness and language-related conditions cannot be extended to cognitive traits in general. 


\section{Conflict of interest}

No conflict of interest to declare.

\section{Funding}

SP and FA are funded by the Royal Society. The UK Medical Research Council and Wellcome (Grant ref: 217065/Z/19/Z) and the University of Bristol provide core support for ALSPAC. This publication is the work of the authors and Silvia Paracchini will serve as guarantors for the reporting of the ALSPAC analysis in this paper. A comprehensive list of grants funding is available on the ALSPAC website (http://www.bristol.ac.uk/alspac/external/documents/grant-acknowledgements.pdf).

\section{Acknowledgements}

We are deeply grateful to the researchers Dr Kucian and Dr McCaskey for sharing unpublished data with us. We would also like to thank Dr Jovanović who kindly translated their study in English for us. Finally, we thank Dr Orly, Dr Bucca, and Dr Ansari for their kind reply to our requests. We are extremely grateful to all the families who took part in this study, the midwives for their help in recruiting them, and the whole ALSPAC team, which includes interviewers, computer and laboratory technicians, clerical workers, research scientists, volunteers, managers, receptionists and nurses. 
HAND PREFERENCE AND MLD

\section{References}

References marked with an asterisk $\left(^{*}\right)$ indicate studies included in the meta-analyses.

American Psychiatric Association (APA). (2013). Diagnostic and statistical manual of mental disorders (DSM-5). Arlington, VA: American Psychiatric Publishing.

American Psychiatric Association (APA). (1994). Diagnostic and statistical manual of mental disorders: DSM-IV 4th ed. Washington (DC): American Psychiatric Association.

*Ashkenazi, S., \& Henik, A. (2010). A disassociation between physical and mental number bisection in developmental dyscalculia. Neuropsychologia, 48(10), 2861-2868. doi: 10.1016/j.neuropsychologia.2010.05.028.

Ashkenazi, S., Rosenberg-Lee, M., Tenison, C., \& Menon, V. (2012). Weak taskrelated modulation and stimulus representations during arithmetic problem solving in children with developmental dyscalculia. Developmental Cognitive Neuroscience, 2, S152-S166.doi: 10.1016/j.dcn.2011.09.006.

Ayyildiz, N., Beyer, F., Üstün, S., Kale, H. E., Çalışır, Ö. M., Uran-Şenol, P., ... \& Villringer, A. (2019). Structural brain connectivity differences of children with and without dyscalculia. In paEpsy Conference.

Bastos, J. A., Cecato, A. M. T., Martins, M. R. I., Grecca, K. R. R., \& Pierini, R. (2016). The prevalence of developmental dyscalculia in Brazilian public school system. Arquivos de Neuro-Psiquiatria, 74(3), 201-206. doi: 10.1590/0004-282X20150212. 
Benbow, C. P. (1988). Sex differences in mathematical reasoning ability in intellectually talented preadolescents: Their nature, effects, and possible causes. Behavioral and Brain Sciences, 11(02), 169-183. doi: 10.1017/S0140525X00049244.

Bishop, D.V., Watt, H., \& Papadatou-Pastou, M. (2009). An efficient and reliable method for measuring cerebral lateralization during speech with functional transcranial Doppler ultrasound. Neuropsychologia,47(2), 587-590. doi: 10.1016/j.neuropsychologia.2008.09.013

Bower, B. (1985). The left hand of math and verbal talent. Science News, 127(17), 263.

Boyd, A., Golding, J., Macleod, J., Lawlor, D. A., Fraser, A., Henderson, J., ... \& Davey Smith, G. (2013). Cohort profile: The 'children of the 90s' — the index offspring of the Avon Longitudinal Study of Parents and Children. International Journal of Epidemiology, 42(1), 111-127.doi: 10.1093/ije/dys064.

Brandler, W. M., Morris, A. P., Evans, D. M., Scerri, T. S., Kemp, J. P., Timpson, N. J., . . Stein, J. (2013). Common variants in left/right asymmetry genes and pathways are associated with relative hand skill. PLoS Genetics, 9(9), e1003751.

Brandler, W. M., \& Paracchini, S. (2014). The genetic relationship between handedness and neurodevelopmental disorders. Trends in Molecular Medicine, 20(2), 83-90. 
*Bucca, A. (2018). Dominanza manuale, disturbi del linguaggio e difficoltà di apprendimento della L2/Manual dominance, language disorders and L2 learning difficulties. Rivista Italiana di Filosofia del Linguaggio, 00. http://160.97.104.70/index.php/rifl/article/view/444.

Butterworth, B. (2005). Developmental dyscalculia. In J. I. D. Campbell (Ed.), Handbook of Mathematical Cognition (pp. 455-468). New York: Psychology Press.

Buenaventura Castillo, C., Lynch, A. G., \& Paracchini, S. (2020). Different laterality indexes are poorly correlated with one another but consistently show the tendency of males and females to be more left-and right-lateralized, respectively. Royal Society Open Science, 7(4), 191700. doi: $10.1098 /$ rsos. 191700

Capano, L., Minden, D., Chen, S. X., Schachar, R. J., \& Ickowicz, A. (2008). Mathematical learning disorder in school-age children with attention-deficit hyperactivity disorder. The Canadian Journal of Psychiatry, 53(6), 392-399. doi: $10.1177 / 070674370805300609$

Chu, F. W., VanMarle, K., \& Geary, D. C. (2015). Early numerical foundations of young children's mathematical development. Journal of Experimental Child Psychology, 132, 205-212. https://doi.org/10.1016/j.jecp.2015.01.006

Cimpian, J. R., Lubienski, S. T., Timmer, J. D., Makowski, M. B., \& Miller, E. K. (2016). Have gender gaps in math closed? Achievement, teacher perceptions, and learning behaviors across two ECLS-K cohorts. AERA Open, 2(4), 2332858416673617. 
Cobley, S., McKenna, J., Baker, J., \& Wattie, N. (2009). How pervasive are relative age effects in secondary school education?. Journal of Educational Psychology, 101(2), 520.doi: 10.1037/a0013845.

Cohen, Z. Z., Gliksman, Y., \& Henik, A. (2019). Modal-independent Pattern Recognition Deficit in Developmental Dyscalculia Adults: Evidence from Tactile and Visual Enumeration. Neuroscience, 423, 109121. doi.org/10.1016/j.neuroscience.2019.10.023

Corballis, M. C., Hattie, J., \& Fletcher, R. (2008). Handedness and intellectual achievement: An even-handed look. Neuropsychologia, 46(1), 374-378.doi: 10.1016/j.neuropsychologia.2007.09.009

Corey, D. M., Hurley, M. M., \& Foundas, A. L. (2001). Right and left handedness defined: A multivariate approach using hand preference and hand performance measures. Cognitive and Behavioral Neurology, 14(3), 144-152.

Crow, T. J., Crow, L. R., Done, D. J., \& Leask, S. (1998). Relative hand skill predicts academic ability: Global deficits at the point of hemispheric indecision. Neuropsychologia, 36(12), 1275-1282. doi: 10.1016/S0028-3932(98)00039-6

Cuellar-Partida, G., Tung, J. Y., Eriksson, N., Albrecht, E., Aliev, F., Andreassen, O. A., ... \& Boyd, H. A. (2020). Genome-wide association study identifies 48 common genetic variants associated with handedness. Nature Human Behaviour, 1-10. doi: 10.1038/s41562-020-00956-y

Dassonville, P., Zhu, X. H., Ugurbil, K., Kim, S. G., \& Ashe, J. (1997). Functional activation in motor cortex reflects the direction and the degree of handedness. Proceedings of the National Academy of Sciences, 94(25), 14015-14018. 
Dennis, M. S., Sorrells, A. M., \& Falcomata, T. S. (2016). Effects of two interventions on solving basic fact problems by second graders with mathematics learning disabilities. Learning Disability Quarterly, 39(2), 95112. doi: $10.1177 / 0731948715595943$

Desoete, A., Roeyers, H., \& De Clercq, A. (2004). Children with mathematics learning disabilities in Belgium. Journal of Learning Disabilities, 37(1), 5061.doi: $10.1177 / 00222194040370010601$

Devine, A., Soltész, F., Nobes, A., Goswami, U., \& Szücs, D. (2013). Gender differences in developmental dyscalculia depend on diagnostic criteria. Learning and Instruction, 27, 31-39. doi: 10.1016/j.learninstruc.2013.02.004

De Visscher, A., \& Noe"1, M.P. (2013). A case study of arithmetic facts dyscalculia caused by a hypersensitivity-to-interference in memory. Cortex, 49(1), 50-70. doi: 10.1016/j.cortex.2012.01.003

Domellöf, E., Johansson, A. M., \& Rönnqvist, L. (2011). Handedness in preterm born children: a systematic review and a meta-analysis. Neuropsychologia, 49(9), 2299-2310. doi: 10.1016/j.neuropsychologia.2011.04.033

Drigas, A., \& Pappas, M. (2015). ICT Based Screening Tools and Etiology of Dyscalculia. International Journal of Engineering Pedagogy (iJEP), 5(3), 6166. doi: 10.3991/i-jep/article/view/4735

Duval, S., \& Tweedie, R. (2000). Trim and fill: a simple funnel-plot-based method of testing and adjusting for publication bias in meta-analysis. Biometrics, 56(2), 455-463. doi: 10.1111/j.0006-341X.2000.00455.x. 
Egger, M., \& Smith, G. D. (1997). Meta-analysis: Potentials and promise. British Medical Journal, 315, 1371-1374.

Evans, T. M., \& Ullman, M. T. (2016). An extension of the procedural deficit hypothesis from developmental language disorders to mathematical disability. Frontiers in Psychology, 7.doi: 10.3389/fpsyg.2016.01318.

Floris, D. L., Lai, M. C., Auer, T., Lombardo, M. V., Ecker, C., Chakrabarti, B., ... \& Suckling, J. (2016). Atypically rightward cerebral asymmetry in male adults with autism stratifies individuals with and without language delay. Human Brain Mapping, 37(1), 230-253. doi: 10.1002/hbm.23023.

Fraser, A., Macdonald-Wallis, C., Tilling, K., Boyd, A., Golding, J., Davey Smith, G., ... \& Ring, S. (2013). Cohort profile: the Avon Longitudinal Study of Parents and Children: ALSPAC mothers cohort. International Journal of Epidemiology, 42(1), 97-110.

Galesic, M., Garcia-Retamero, R., \& Gigerenzer, G. (2009). Using icon arrays to communicate medical risks: Overcoming low numeracy. Health Psychology, 28(2), 210. doi: 10.1037/a0014474

Geary, D. C. (2004). Mathematics and learning disabilities. Journal of Learning Disabilities, 37(1), 4-15. doi: 10.1177/00222194040370010201.

Geary, D. C., Bailey, D. H., Littlefield, A., Wood, P., Hoard, M. K., \& Nugent, L. (2009). First-grade predictors of mathematical learning disability: A latent class trajectory analysis. Cognitive Development, 24(4), 411-429. https://doi.org/10.1016/j.cogdev.2009.10.001

Gómez-Velázquez, F. R., Vélez-Pérez, H., Espinoza-Valdez, A., Romo-Vazquez, R., Salido-Ruiz, R. A., Ruiz-Stovel, V., ... \& Berumen, G. (2017). 
Electrophysiological dynamic brain connectivity during symbolic magnitude comparison in children with different mathematics achievement levels. NeuroReport, 28(3), 174-178.doi: 10.1097/WNR.0000000000000722.

Gonzalez, C.L., \& Goodale, M.A., 2009. Hand preference for precision grasping predicts language lateralization. Neuropsychologia, 47(14), 3182-3189. doi: 10.1016/j.neuropsychologia.2009.07.019.

González-Garrido, A. A., Gómez-Velázquez, F. R., Salido-Ruiz, R. A., EspinozaValdez, A., Vélez-Pérez, H., Romo-Vazquez, R., ... \& Berumen, G. (2018). The analysis of EEG coherence reflects middle childhood differences in mathematical achievement. Brain and Cognition, 124, 57-63.doi: 10.1016/j.bandc.2018.04.006.

Grabner, R. H., \& Ansari, D. (2010). Promises and potential pitfalls of a 'cognitive neuroscience of mathematics learning'. ZDM Mathematics Education, 42(6), doi: 655-660.10.1007/s11858-010-0283-4.

Grabner, R.H., Ischebeck, A., Reishofer, G., Koschutnig, K., Delazer, M., Ebner, F., \& Neuper, C. (2009). Fact learning in complex arithmetic and figural-spatial tasks: the role of the angular gyrus and its relation to mathematical competence.Human Brain Mapping, 30(9), 2936-52.doi: 10.1002/hbm.20720

*Greiffenstein, M. F., \& Baker, W. J. (2002). Neuropsychological and psychosocial correlates of adult arithmetic deficiency. Neuropsychology, 16(4), 451458.doi: 10.1037/0894-4105.16.4.451.

Gross-Tsur, V., Manor, O., \& Shalev, R. S. (1996). Developmental dyscalculia: Prevalence and demographic features. Developmental Medicine \& Child Neurology, 38(1), 25-33.doi: 10.1111/j.1469-8749.1996.tb15029.x. 
Gundogan, N. U., Kiziltan, E., Aydin, L., \& Ogus, E. (2016). Effects of mental activity on hand skill rate performance ability among second grader medical students. Open Access Library Journal, 3(01), 1.doi: 10.4236/oalib.1102275.

Güntürkün, O., \& Ocklenburg, S. (2017). Ontogenesis of lateralization. Neuron, 94(2), 249-263.

Hein, J., Bzufka, M. W., \& Neumärker, K. J. (2000). The specific disorder of arithmetic skills.Prevalence studies in a rural and an urban population sample and their clinico-neuropsychological validation. European Child \& Adolescent Psychiatry, 9, S87-S101.doi: 10.1007/s007870070012.

Hesesport (2015). Tap Test Pro (Version 1.0.0) [Mobile application software]. Retrieved from https://play.google.com/store/apps/details? $\mathrm{id}=$ com.hesesport.taptestpro\&hl=de Higgins, J., Thompson, S. G., Deeks, J. J., \& Altman, D. G. (2003). Measuring inconsistency in meta-analyses. British Medical Journal, 327, 557-560.

Hsieh, M. T., Lai, M. C., Lin, K. M., \& Huang, C. W. (2017). Late-onset non lesional non dominant frontal lobe seizures presenting as ictal dyscalculia. The Kaohsiung Journal of Medical Sciences, 33(1), 52-54.doi: 10.1016/j.kjms.2016.08.005.

Hoffmann, D., Mussolin, C., Martin, R., \& Schiltz, C. (2014). The impact of mathematical proficiency on the number-space association. PLoS One, 9(1), e85048. doi: 10.1371/journal.pone.0085048.

Huber, S., Nuerk, H. C., Reips, U. D., \& Soltanlou, M. (2017). Individual differences influence two-digit number processing, but not their analog magnitude 
processing: A large-scale online study. Psychological Research, 1-21. doi: $10.1007 / \mathrm{s} 00426-017-0964-5$.

Hunter, J. E., \& Schmidt, F. L. (1990). Dichotomization of continuous variables: The implications for meta-analysis. Journal of Applied Psychology, 75(3), 334349.doi: $10.1037 / 0021-9010.75 .3 .334$.

IBM Corp. Released 2017. IBM SPSS Statistics for Windows, Version 25.0. Armonk, NY: IBM Corp.

Isaacs, E. B., Edmonds, C. J., Lucas, A., \& Gadian, D. G. (2001).Calculation difficulties in children of very low birth weight. Brain, 124(9), 1701-1707.doi: 10.1093/brain/124.9.1701

Isaacs, K.L., Barr, W.B., Nelson, P.K., \& Devinsky, O. (2006). Degree of handedness and cerebral dominance. Neurology, 66(12), 1 855-1858. doi: 10.1212/01.wnl. 0000219623.28769 .74

Iuculano, T., \& Cohen Kadosh, R. (2014). Preliminary evidence for performance enhancement following parietal lobe stimulation in developmental dyscalculia. Frontiers in Human Neuroscience, 8, 38.doi: 10.3389/fnhum.2014.00038

*Jastrzebski, N. R., Crewther, S. G., \& Crewther, D. P. (2015). Mathematical impairment associated with high-contrast abnormalities in change detection and magnocellular visual evoked response. Experimental Brain Research, 233(10), 3039-3046.doi: 10.1007/s00221-015-4373-y

Johnston, D. W., Nicholls, M. E., Shah, M., \& Shields, M. A. (2013). Handedness, health and cognitive development: evidence from children in the National 
Longitudinal Survey of Youth. Journal of the Royal Statistical Society: Series A (Statistics in Society), 176(4), 841-860. doi: 10.1111/j.1467985X.2012.01074.X

Johnston, D. W., Nicholls, M. E., Shah, M., \& Shields, M. A. (2009). Nature's experiment? Handedness and early childhood development. Demography, 46(2), 281-301.doi: 10.1353/dem.0.0053

Jovanović, G., Jovanović, Z., Banković-Gajić, J., Nikolić, A., Svetozarević, S., \& Ignjatović-Ristić, D. (2013).The frequency of dyscalculia among primary school children. Psychiatria Danubina, 25(2), 0-174. doi: 10.1353/dem.0.0053

*Jovanović, G., Purić, B., \& Ignjatović-Ristić, D. (2014). Influence of dominant laterality limbs and senses on dyscalculia. Medicinski Casopis, 48(1), 711.doi: $10.5937 / \mathrm{mckg} 48-3905$

Kaufman, A. S. \& Kaufman, N. L. (2015). Kaufman Assessment Battery for Children2 (KABC-II). (P. Melchers \& M. Melchers, Eds.). Göttingen: Hogrefe.

Kaufmann, L., Nuerk, H.-C., Graf, M., Krinzinger, H., Delazer, M., \& Willmes, K. (2009). TEDI-MATH. Test zur Erfassung numerisch-rechnerischer Fertigkeiten vom Kindergarten bis zur 3. Klasse [Test for assessment of numerical and calculation skills from preschool to third grade]. Bern: Hans Huber.

Karagiannakis, G., Baccaglini-Frank, A., \& Papadatos, Y. (2014). Mathematical learning difficulties subtypes classification. Frontiers in Human Neuroscience, 8, 57. doi: 10.3389/fnhum.2014.00057. 
Kawaguchi, D. (2011). Actual age at school entry, educational outcomes, and earnings. Journal of the Japanese and International Economies, 25(2), 64-80. doi: 10.1016/j.jjie.2009.02.002.

Kessels, R. P. C., Zandvoort, M. J. E. van, Postma, A., Kappelle, L. J., \& Haan, E. H. F. de. (2000). The Corsi Block-Tapping Task: Standardization and Normative Data. Applied Neuropsychology, 7(4), 252-258. https://doi.org/10.1207/S15324826AN0704

Khedr, E. M., Hamed, E., Said, A., \& Basahi, J. (2002). Handedness and language cerebral lateralization. European Journal of Applied Physiology, 87(4), 469473.doi: 10.1007/s00421-002-0652-y.

Knecht, S., Dräger, B., Deppe, M., Bobe, L., Lohmann, H., Flöel, A., Ringelstein, E.B., \& Henningsen, H. (2000).Handedness and hemispheric language dominance in healthy humans. Brain, 123(12), 2512-2518. doi:10.1093/brain/123.12.2512

Koerte, I. K., Willems, A., Muehlmann, M., Moll, K., Cornell, S., Pixner, S., Steffinger, D., Keeser, D., Heinen, F., Kubicki, M., Shenton, M. E., ErtlWagner B., \& Schulte-Körne G. (2016). Mathematical abilities in dyslexic children: a diffusion tensor imaging study. Brain Imaging and Behavior, 10(3), 781-791. doi: 10.1007/s11682-015-9436-y.

Koumoula, A., Tsironi, V., Stamouli, V., Bardani, I., Siapati, S., Annika, G., Kafantaris, I., Charalambidou, I., Dellatolas, G., \& von Aster, M. (2004). An epidemiological study of number processing and mental calculation in Greek schoolchildren. Journal of Learning Disabilities 37, 377-388. 
Koontz, K. L. (1996). Identifying simple numerical stimuli: Processing inefficiencies exhibited by arithmetic learning disabled children. Mathematical Cognition, 2(1), 1-24.doi: 10.1080/135467996387525

Kosc, L. (1974). Developmental dyscalculia. Journal of Learning Disabilities, 7(3), 164-177.doi: 10.1177/002221947400700309

Koumoula, A., Tsironi, V., Stamouli, V., Bardani, I., Siapati, S., Graham, A., ... \& von Aster, M. (2004).An epidemiological study of number processing and mental calculation in Greek schoolchildren. Journal of Learning Disabilities, 37(5), 377-388. doi: 10.1177/00222194040370050201

*Kovas, Y., Giampietro, V., Viding, E., Ng, V., Brammer, M., Barker, G. J., Happe, F.G.E., \& Plomin, R. (2009). Brain correlates of non-symbolic numerosity estimation in low and high mathematical ability children. PLoS One, 4(2), e4587. doi: 10.1371/journal.pone.0004587.

*Kucian, K. (2018). Developmental Dyscalculia. Unpublished raw data.

*Kucian, K., Ashkenazi, S. S., Hänggi, J., Rotzer, S., Jäncke, L., Martin, E., \& von Aster, M. (2014). Developmental dyscalculia: a disconnection syndrome?. Brain Structure and Function, 219(5), 1721-1733. doi: 10.1007/s00429-013-0597-4

*Kucian, K., Grond, U., Rotzer, S., Henzi, B., Schönmann, C., Plangger, F. ... \& \& von Aster, M. (2011a). Mental number line training in children with developmental dyscalculia. Neuroimage, 57(3), 782-795.doi:

10.1016/j.neuroimage.2011.01.070 
Kucian, K., Loenneker, T., Dietrich, T., Dosch, M., Martin, E., \& von Aster, M. (2006). Impaired neural networks for approximate calculation in dyscalculic children: a functional MRI study. Behavioral and Brain Functions: BBF, 2, 31-31. doi: 10.1186/1744-9081-2-31

Kucian, K., Loenneker, T., Martin, E., \& von Aster, M. (2011b). Non-symbolic numerical distance effect in children with and without developmental dyscalculia: a parametric fMRI study. Developmental Neuropsychology, 36(6), 741-762. doi: 10.1080/87565641.2010.549867

Lafay, A., Macoir, J., \& St-Pierre, M. C. (2018). Impairment of arabic-and spokennumber processing in children with Mathematical Learning Disability. Journal of Numerical Cognition, 3(3), 620-641. doi: 10.5964/jnc.v3i3.123

*Lafay, A., St-Pierre, M. C., \& Macoir, J. (2017). The mental number line in dyscalculia: Impaired number sense or access from symbolic numbers?. Journal of Learning Disabilities, 50(6), 672-683. doi:10.1177/0022219416640783.

Lewis, K. E., \& Fisher, M. B. (2016). Taking stock of 40 years of research on mathematical learning disability: Methodological issues and future directions. Journal for Research in Mathematics Education, 47, 338-371. doi: 10.5951/jresematheduc.47.4.0338

Lindberg, S. M., Hyde, J. S., Petersen, J. L., \& Linn, M. C. (2010). New trends in gender and mathematics performance: A meta-analysis. Psychological Bulletin, 136(6), 1123.doi: 10.1037/a0021276.

Lyons, I. M., Price, G. R., Vaessen, A., Blomert, L., \& Ansari, D. (2014). Numerical 
predictors of arithmetic success in grades 1-6. Developmental Science, 17(5), 714-726. https://doi.org/10.1111/desc. 12152

Markou, P., Ahtam, B., \& Papadatou-Pastou, M. (2017). Elevated levels of atypical handedness in autism: Meta-analyses. Neuropsychology Review, 27(3), 258283. doi: 10.1007/s11065-017-9354-4

Martins, I.P., Ferreira, J., \& Borges, L. (1999). Acquired procedural dyscalculia associated to a left parietal lesion in a child. Child Neuropsychololy, 5, 265273. doi: 10.1076/0929-7049

Mazoyer, B., Zago, L., Jobard, G., Crivello, F., Joliot, M., Perchey, G., ... \& TzourioMazoyer, N. (2014). Gaussian mixture modeling of hemispheric lateralization for language in a large sample of healthy individuals balanced for handedness. PloS One, 9(6), e101165.

Mazzocco, M. M., \& Thompson, R. E. (2005). Kindergarten predictors of math learning disability. Learning Disabilities Research \& Practice, 20(3), 142155. doi: $10.1007 / \mathrm{s} 11881-003-0011-7$

*McCaskey, M.R. (2018a). Longitudinal data. Unpublished raw data.

*McCaskey, M.R. (2018b). Longitudinal data. Unpublished raw data.

McCaskey, U., Von Aster, M., O’Gorman Tuura, R., \& Kucian, K. (2017).

Adolescents with developmental dyscalculia do not have a generalized magnitude deficit-processing of discrete and continuous magnitudes. Frontiers in Human Neuroscience, 11, 102. doi: 10.3389/fnhum.2017.00102

McCaskey, U., von Aster, M., Maurer, U., Martin, E., O'Gorman Tuura, R., \& Kucian, K. (2018). Longitudinal brain development of numerical skills in 
typically developing children and children with developmental dyscalculia. Frontiers in Human Neuroscience, 11, 629.doi: 10.3389/fnhum.2017.00629

McLean, J. F., \& Hitch, G. J. (1999). Working memory impairments in children with specific arithmetic learning difficulties. Journal of Experimental Child Psychology, 74(3), 240-260.doi: 10.1006/jecp.1999.2516

McManus, I. C., Murray, B., Doyle, K., \& Baron-Cohen, S. (1992). Handedness in childhood autism shows a dissociation of skill and preference. Cortex, 28, 373-381.https://doi.org/10.1016/S0010-9452(13)80147-5

Michel, G. F., Babik, I., Nelson, E. L., Campbell, J. M., \& Marcinowski, E. C. (2018). Evolution and development of handedness: An Evo-Devo approach. Progress in Brain Research 238, 347-374.

Michels, L., O’Gorman, R., \& Kucian, K. (2018). Functional hyperconnectivity vanishes in children with developmental dyscalculia after numerical intervention. Developmental Cognitive Neuroscience, 30, 291-303. doi: 10.1016/j.den.2017.03.005

Miller, H., \& Bichsel, J. (2004). Anxiety, working memory, gender, and math performance. Personality and Individual Differences, 37(3), 591-606.

Miller, Z. A., Rosenberg, L., Santos-Santos, M. A., Stephens, M., Allen, I. E., Hubbard, H. I., ..., \& Gorno-Tempini, M.L. (2018). Prevalence of mathematical and visuospatial learning disabilities in patients with posterior cortical atrophy. JAMA Neurology, 75(6), 728-737. doi:

10.1001/jamaneurol.2018.0395 
Mohammadi, H., \& Papadatou-Pastou, M. (2019) Cerebral laterality as assessed by hand preference and developmental stuttering. Laterality: Asymmetries of Body, Brain and Cognition, (in press). doi: 10.1080/1357650X.2019.1621329

Moher, D., Liberati, A., Tetzlaff, J., Altman, D. G., \& Prisma Group. (2009). Preferred reporting items for systematic reviews and meta-analyses: The PRISMA statement. PLoS Med, 6(7), e1000097. doi: 10.1371/journal.pmed.1000097

Morsanyi, K., van Bers, B. M. C. W., McCormack, T., \& McGourty, J. (2018). The prevalence of specific learning disorder in mathematics and comorbidity with other developmental disorders in primary school-age children. British Journal of Psychology, 109, 917-940. doi: 10.1111/bjop.12322

Moser, I., Vibert, D., Caversaccio, M. D., \& Mast, F. W. (2017a). Acute peripheral vestibular deficit increases redundancy in random number generation. Experimental Brain Research, 235(2), 627-637. doi: 10.1007/s00221-0164829-8

Moser, I., Vibert, D., Caversaccio, M. D., \& Mast, F. W. (2017b). Impaired math achievement in patients with acute vestibular neuritis. Neuropsychologia, 107, 1-8. doi: 10.1016/j.neuropsychologia.2017.10.032

Newbury, D. F., Monaco, A. P., \& Paracchini, S. (2014). Reading and language disorders: The importance of both quantity and quality. Genes (Basel), 5, 285309. doi: $10.3390 /$ genes 5020285

Nicholls, M. E., Chapman, H. L., Loetscher, T., \& Grimshaw, G. M. (2010). The relationship between hand preference, hand performance, and general cognitive ability. Journal of the International Neuropsychological Society, $16(4), 585-592$. 
Ntolka, E., \& Papadatou-Pastou, M. (2017). Right-handers have negligibly higher Iq scores than left-handers: Systematic review and meta-analyses. Neuroscience \& Biobehavioral Reviews, 84, 376-393.doi:10.1016/j.neubiorev.2017.08.007

Nunes, T., Bryant, P., Barros, R., \& Sylva, K. (2012). The relative importance of two different mathematical abilities to mathematical achievement. British Journal of Educational Psychology, 82(1), 136-156.doi: 10.1111/j.20448279.2011.02033.x.

O'Connell, M. (2018). The power of cognitive ability in explaining educational test performance, relative to other ostensible contenders. Intelligence, 66, 122127.DOI: 10.1016/j.intell.2017.11.011

OECD. (2019). Education at a Glance 2019: OECD Indicators. Paris: OECD Publishing. doi: 10.1787/f8d7880d-en.

Oldfield, R. C. (1971). The assessment and analysis of handedness: the Edinburgh inventory. Neuropsychologia, 9(1), 97-113.doi: 10.1016/0028-3932(71)900674.

Open Science Collaboration (2015). Estimating the reproducibility of psychological science. Science, 349(6251), aac4716.

Papadatou-Pastou, M. (2018) Handedness and cognitive ability: Using meta-analysis to make sense of the data. Progress in Brain Research, 238, 179-206.

Papadatou-Pastou, M. (2011). Handedness and language lateralization: Why are we right-handed and left-brained. Hellenic Journal of Psychology, 8, 248-265. 
Papadatou-Pastou, M., Martin, M., \& Munafò, M. R. (2013). Measuring hand preference: A comparison among different response formats using a selected sample, Laterality, 18(1), 68-107. doi: 10.1080/1357650X.2011.628794

Papadatou-Pastou, M., Ntolka, E., Schmitz, J., Martin, M., Munafò, M. R., Ocklenburg, S., \& Paracchini, S. (2020). Human handedness: A meta-analysis. Psychological Bulletin, 146(6), 481-524.https://doi.org/10.1037/bu10000229

Papadatou-Pastou, M., Martin, M., Munafo, M. R., \& Jones, G. V. (2008). Sex differences in left-handedness: a meta-analysis of 144 studies. Psychological Bulletin, 134(5), 677-699. doi: 10.1037/a0012814

Papadatou-Pastou, M., \& Sáfár, A. (2016). Handedness prevalence in the deaf: Metaanalyses. Neuroscience \& Biobehavioral Reviews, 60, 98-114.doi: 10.1016/j.neubiorev.2015.11.013

Papadatou-Pastou, M., \& Tomprou, D. M. (2015). Intelligence and handedness: Metaanalyses of studies on intellectually disabled, typically developing, and gifted individuals. Neuroscience \& Biobehavioral Reviews, 56, 151-165.doi: 10.1016/j.neubiorev.2015.06.017

Pettigrew, K. A., Fajutrao Valles, S. F., Moll, K., Northstone, K., Ring, S., Pennell, C., ... \& Simpson, N. H. (2015). Lack of replication for the myosin-18B association with mathematical ability in independent cohorts. Genes, Brain and Behavior, 14(4), 369-376. doi: 10.1111/gbb.12213.

Pinel, P., \& Dehaene, S. (2010). Beyond Hemispheric Dominance: Brain Regions Underlying the Joint Lateralization of Language and Arithmetic to the Left Hemisphere. Journal of Cognitive Neuroscience, 22(1), 48-66.doi:

10.1162/jocn.2009.21184 
*Price, G. R., Holloway, I., Räsänen, P., Vesterinen, M., \& Ansari, D. (2007). Impaired parietal magnitude processing in developmental dyscalculia. Current Biology, 17(24), R1042-R1043.doi: 10.1016/j.cub.2007.10.013

Pritchard, V. E., Malone, S.A., Burgoyne, K., Burgoyne, K., Heron-Delaney, M., \& Bishop, D.V.M. (2019). Stage 1 Registered Report: The relationship between handedness and language ability in children [version 1; peer review: 2 approved]. Wellcome Open Research, 4:30. doi:10.12688/wellcomeopenres.15077.1)

Prichard, E., Propper, R. E., \& Christman, S. D. (2013). Degree of handedness, but not direction, is a systematic predictor of cognitive performance. Frontiers in Psychology, 4, 9.doi: 10.3389/fpsyg.2013.00009

R Core Team (2018) 'R: A Language and Environment for Statistical Computing'. R Foundation for Statistical Computing, Vienna, Austria. URL https://www.r-project.org.

Ramaa, S., \& Gowramma, I. (2002). A systematic procedure for identifying and classifying children with dyscalculia among primary school children in India. Dyslexia, 8(2), 67-85.doi: 10.1002/dys.214

Reigosa-Crespo, V., Valdés-Sosa, M., Butterworth, B., Estévez, N., Rodríguez, M., Santos, E., ... \& Lage, A. (2012). Basic numerical capacities and prevalence of developmental dyscalculia: The Havana Survey. Developmental Psychology, 48(1), 123.doi: 10.1037/a0025356

Rodriguez, A., Kaakinen, M., Moilanen, I., Taanila, A., McGough, J. J., Loo, S., \& Järvelin, M. R. (2010). Mixed-handedness is linked to mental health problems 
in children and adolescents. Pediatrics, 125(2), e340-e348.doi:

10.1542/peds.2009-1165

Rosenberg, P. B. (1989). Perceptual-motor and attentional correlates of developmental dyscalculia. Annals of Neurology, 26(2), 216-220.doi: 10.1002/ana.410260206

Rosenthal, R., \& DiMatteo, M. R. (2001). Meta-analysis: Recent developments in quantitative methods for literature reviews. Annual Review of Psychology, 52, 59-82. doi: 10.1146/annurev.psych.52.1.59

*Rotzer, S., Kucian, K., Martin, E., von Aster, M., Klaver, P., \& Loenneker, T. (2008). Optimized voxel-based morphometry in children with developmental dyscalculia. Neuroimage, 39(1), 417-422. doi:

10.1016/j.neuroimage.2007.08.045

Rotzer, S., Loenneker, T., Kucian, K., Martin, E., Klaver, P., \& Von Aster, M. (2009). Dysfunctional neural network of spatial working memory contributes to developmental dyscalculia. Neuropsychologia, 47(13), 2859-2865.doi: 10.1016/j.neuropsychologia.2009.06.009

*Rubinsten, O., \& Henik, A. (2006). Double dissociation of functions in developmental dyslexia and dyscalculia. Journal of Educational Psychology, 98(4), 854-867.doi: 10.1037/0022-0663.98.4.854

Rykhlevskaia, E., Uddin, L. Q., Kondos, L., \& Menon, V. (2009). Neuroanatomical correlates of developmental dyscalculia: Combined evidence from morphometry and tractography. Frontiers in Human Neuroscience, 3, 51. 
Sala, G., Signorelli, M., Barsuola, G., Bolognese, M., \& Gobet, F. (2017). The relationship between handedness and mathematics is non-linear and is moderated by gender, age, and type of task. Frontiers in Psychology, 8, 948. doi: 10.3389/fpsyg.2017.00948

Salvador, L. D. S., Moura, R., Ferreira, F. O., Andrade, P. M. O., Carvalho, M. R. S., \& Haase, V. G. (2019). The Mini-Mental Examination for Children (MMC): Evidence of validity for children with learning difficulties. Dementia \& Neuropsychologia, 13(4), 427-435.doi.org/10.1590/1980-57642018dn13$\underline{040010}$

Scerri, T. S., Morris, A. P., Buckingham, L. L., Newbury, D. F., Miller, L. L., Monaco, A. P., ... \& Paracchini, S. (2011). DCDC2, KIAA0319 and CMIP are associated with reading-related traits. Biological Psychiatry, 70(3), 237-245. doi: 10.1016/j.biopsych.2011.02.005

Semenza, C., Delazer, M., Bertella, L., Grana, A., Mori, I., Conti, F. M., Pignatti, R., Bartha, L., Domahs, F., Benke, T., \& Mauro, A. (2006). Is math lateralised on the same side as language? Right hemisphere aphasia and mathematical abilities. Neuroscience Letters, 406(3), 285-288.doi:

10.1016/j.neulet.2006.07.063

*Shalev, R. S., Manor, O., Amir, N., Wertman-Elad, R., \& Gross-Tsur, V. (1995). Developmental dyscalculia and brain laterality. Cortex, 31(2), 357-365.doi: 10.1016/S0010-9452(13)80368-1 
Shalev, R. S., Manor, O., \& Gross-Tsur, V. (1997). Neuropsychological aspects of developmental dyscalculia. Mathematical Cognition, 3(2), 105-120.doi: $10.1080 / 135467997387434$

Sherman, J. (1979). Cognitive performance as a function of sex and handedness: An evaluation of the Levy hypothesis. Psychology of Women Quarterly, 3(4), 378390.doi: 10.1111/j.1471-6402.1979.tb00687.x

Sideridis, G., Antoniou, F., Simos, P., \& Mouzaki, A. (2015). Raven's Colour Progressive Matrices, Greek Standardization. Athina: Motibo

*Skeide, M. A., Evans, T. M., Mei, E. Z., Abrams, D. A., \& Menon, V. (2018). Neural signatures of co-occurring reading and mathematical difficulties. Developmental Science, e12680. doi: 10.1111/desc.12680

Sommer, I. E. C., Ramsey, N. F., Mandl, R. C. W., \& Kahn, R. S. (2002). Language lateralization in monozygotic twin pairs concordant and discordant for handedness. Brain, 125(12), 2710-2718. doi:10.1093/brain/awf284

Somers, M., Aukes, M. F., Ophoff, R. A., Boks, M. P., Fleer, W., Kahn, R. S., \& Sommer, I. E. (2015). On the relationship between degree of hand-preference and degree of language lateralization. Brain and Language, 144, 10-15.

*Spellacy, F., \& Peter, B. (1978). Dyscalculia and elements of the developmental Gerstmann syndrome in school children. Cortex, 14(2), 197-206.doi: $10.1016 / \mathrm{S} 0010-9452(78) 80045-8$

Spreen, O., \& Gaddes, W. H. (1969). Development norms for 15 neuropsychological tests age 6 to 15. Cortex, 5, 171-191. https://doi.org/10.1016/S00109452(69)80028-6 
Stanescu-Cosson, R., Pinel, P., van de Moortele, P. F., Le Bihan, D., Cohen, L., \& Dehaene, S. (2000). Understanding dissociations in dyscalculia: A brain imaging study of the impact of number size on the cerebral networks for exact and approximate calculation. Brain, 123(11), 2240-2255.doi: 10.1093/brain/123.11.2240

Steenhuis, R. E., \& Bryden, M. P. (1989). Different dimensions of hand preference that relate to skilled and unskilled activities. Cortex, 25(2), 289-304.doi: org/10.1016/S0010-9452(89)80044-9

Stock, P., Desoete, A., \& Roeyers, H. (2010). Detecting children with arithmetic disabilities from kindergarten: evidence from a 3-year longitudinal study on the role of preparatory arithmetic abilities. Journal of Learning Disabilities, 43(3), 250-268. https://doi.org/10.1177/0022219409345011

Strang, J. D., \& Rourke, B.P. (1983). Concept-formation/non-verbal reasoning abilities of children who exhibit specific academic problems with arithmetic. Journal of Clinical Child Psychology, 12(1), 33-39.doi:

$10.1080 / 15374418309533110$

Träff, U., Olsson, L., Östergren, R., \& Skagerlund, K. (2016). Heterogeneity of developmental dyscalculia: Cases with different deficit profiles. Frontiers in Psychology, 7, 2000.doi: 10.3389/fpsyg.2016.02000

Tran, U. S., \& Voracek, M. (2015). Schizophrenia and mixed-handedness. The British Journal of Psychiatry, 207(2), 178-178.doi: 10.1192/bjp.207.2.178

Triggs, W. J., Calvanio, R., Levine, M., Heaton, R. K., \& Heilman, K. M. (2000). Predicting hand preference with performance on motor tasks. Cortex, 36(5), 679-689. https://doi.org/10.1016/S0010-9452(08)70545-8 
Uomini, N. T., \& Ruck, L. (2018). Manual laterality and cognition through evolution: An archeological perspective. Progress in Brain Research, 238, 295-323.

Verly, M., Gerrits, R., Sleurs, C., Lagae, L., Sunaert, S., Zink, I., \&Rommel, N. (2018). The mis-wired language network in children with developmental language disorder: insights from DTI tractography. Brain Imaging and Behavior, 1-12. 10.1007/s11682-018-9903-3

Vlachos, F., Andreou, E., Delliou, A., \& Agapitou, P. (2013). Dyslexia and hand preference in secondary school students. Psychology \& Neuroscience, 6(1), 67-72.doi: 10.3922/j.psns.2013.1.10

von Aster, M. (2000). Developmental cognitive neuropsychology of number processing and calculation: Varieties of developmental dyscalculia. European Child \& Adolescent Psychiatry, 9(Suppl 2), 41-57. doi: $10.1007 / \mathrm{s} 007870070008$

von Aster, M. (2001). Die neuropsychologische Testbatterie für Zahlenverarbeitung und Rechnen bei Kindern (ZAREKI). [The neuropsychological test battery for number processing and calculation in children (NUCALC)]. Frankfurt, Germany: Swets \& Zeitliger.

Walker, E., Hernandez, A. V., \& Kattan, M. W. (2008). Meta-analysis: its strengths and limitations. Cleveland Clinic Journal of Medicine, 75(6), 431-439.

White, G., Ruther, M., \& Kahn, J. (2016). Educational Inequality in India: An Analysis of Gender Differences in Reading and Mathematics. IHDS Working Paper 2016-2. 
Whittington, J. E., \& Richards, P. N. (1991). Mathematical ability and the right-shift theory of handedness. Neuropsychologia, 29(11), 1075-1082.doi: 10.1016/0028-3932(91)90077-L

Wiberg, A. Douaud, A, Ng, M., Al Omran, Y., Alfaro-Almagro, F., Marchini, J., Bennett, D.L., Smith, S., \& Furniss, D. (2018, October 26). Human handedness: Genetics, microtubules, neuropsychiatric diseases and brain language areas, https://doi.org/10.1101/454660

Wechsler, D. (1991). The Wechsler intelligence scale for children-third edition. San Antonio, TX: The Psychological Corporation.

Wechsler, D., Golombok, S., \& Rust, J. (1992). WISC-III UK Wechsler intelligence scale for children: UK manual. Sidcup, UK: The Psychological Corporation.

Wong, T. T. Y., Ho, C. S. H., \& Tang, J. (2017). Defective number sense or impaired access? Differential impairments in different subgroups of children with mathematics difficulties. Journal of Learning Disabilities, 50(1), 49-61.doi: $10.1177 / 0022219415588851$

Woolger, C. (2001) 'Wechsler Intelligence Scale for Children-Third Edition (wisciii)', in Understanding Psychological Assessment. doi: 10.1007/978-1-46151185-4_11.

*Zergiotis, A. (2004).Intervention Program to Improving Memory and Basic Arithmetic Skills for Children with learning disabilities in Mathematics.(Unpublished doctoral dissertation). National and Kapodistrian University, Athens. 
HAND PREFERENCE AND MLD 
HAND PREFERENCE AND MLD

Table 1.

Hands preferred for the four actions by males and females in the two groups for Study 1.

\begin{tabular}{|c|c|c|c|c|c|c|c|}
\hline & & \multicolumn{3}{|c|}{$\begin{array}{c}\text { Learning Difficulties in } \\
\text { Mathematics }\end{array}$} & \multicolumn{3}{|c|}{ Typically Achieving } \\
\hline & & Right & Both & Left & Right & Both & Left \\
\hline \multirow[t]{4}{*}{ Males } & Writing hand & $\begin{array}{c}16 \\
(84.2 \%)\end{array}$ & - & $\begin{array}{c}3 \\
(15.8 \%)\end{array}$ & $\begin{array}{c}39 \\
(92.9 \%)\end{array}$ & - & $\begin{array}{c}3 \\
(7.1 \%)\end{array}$ \\
\hline & Drawing hand & $\begin{array}{c}15 \\
(78.9 \%)\end{array}$ & $\begin{array}{c}2 \\
(10.5 \%)\end{array}$ & $\begin{array}{c}2 \\
(10.5 \%)\end{array}$ & $\begin{array}{c}36 \\
(85.7 \%)\end{array}$ & $\begin{array}{c}4 \\
(9.5 \%)\end{array}$ & $\begin{array}{c}2 \\
(4.8 \%)\end{array}$ \\
\hline & $\begin{array}{l}\text { Throwing } \\
\text { hand }\end{array}$ & $\begin{array}{c}12 \\
(63.2 \%)\end{array}$ & $\begin{array}{c}5 \\
(26.3 \%)\end{array}$ & $\begin{array}{c}2 \\
(10.5 \%)\end{array}$ & $\begin{array}{c}18 \\
(42.9 \%)\end{array}$ & $\begin{array}{c}19 \\
(45.2 \%)\end{array}$ & $\begin{array}{c}5 \\
(11.9 \%)\end{array}$ \\
\hline & $\begin{array}{l}\text { Hand using } \\
\text { computer } \\
\text { mouse }\end{array}$ & $\begin{array}{c}16 \\
(84.2 \%)\end{array}$ & $\begin{array}{c}2 \\
(10.5 \%)\end{array}$ & $\begin{array}{c}1 \\
(5.3 \%)\end{array}$ & $\begin{array}{c}38 \\
(90.5 \%)\end{array}$ & $\begin{array}{c}4 \\
(9.5 \%)\end{array}$ & $\begin{array}{c}0 \\
(0 \%)\end{array}$ \\
\hline \multirow[t]{4}{*}{ Females } & Writing hand & $\begin{array}{c}21 \\
(80.8 \%)\end{array}$ & $\begin{array}{c}1 \\
(3.8 \%)\end{array}$ & $\begin{array}{c}4 \\
(15.4 \%)\end{array}$ & $\begin{array}{c}44 \\
(93.6 \%)\end{array}$ & - & $\begin{array}{c}3 \\
(6.4 \%)\end{array}$ \\
\hline & Drawing hand & $\begin{array}{c}19 \\
(73.1 \%)\end{array}$ & $\begin{array}{c}3 \\
(11.5 \%)\end{array}$ & $\begin{array}{c}4 \\
(15.4 \%)\end{array}$ & $\begin{array}{c}39 \\
(83 \%)\end{array}$ & $\begin{array}{c}5 \\
(10.6 \%)\end{array}$ & $\begin{array}{c}3 \\
(6.4 \%)\end{array}$ \\
\hline & $\begin{array}{l}\text { Throwing } \\
\text { hand }\end{array}$ & $\begin{array}{c}9 \\
(34.6 \%)\end{array}$ & $\begin{array}{c}16 \\
(61.5 \%)\end{array}$ & $\begin{array}{c}1 \\
(11.5 \%)\end{array}$ & $\begin{array}{c}20 \\
(42.6 \%)\end{array}$ & $\begin{array}{c}24 \\
(51 \%)\end{array}$ & $\begin{array}{c}3 \\
(6.4 \%)\end{array}$ \\
\hline & $\begin{array}{l}\text { Hand using } \\
\text { computer } \\
\text { mouse }\end{array}$ & $\begin{array}{c}20 \\
(76.9 \%)\end{array}$ & $\begin{array}{c}4 \\
(15.4 \%)\end{array}$ & $\begin{array}{c}2 \\
(7.7 \%)\end{array}$ & $\begin{array}{c}36 \\
(76.6 \%)\end{array}$ & $\begin{array}{c}8 \\
(17 \%)\end{array}$ & $\begin{array}{c}3 \\
(6.4 \%)\end{array}$ \\
\hline \multirow[t]{4}{*}{ Total } & Writing hand & $\begin{array}{c}37 \\
(82.2)\end{array}$ & $\begin{array}{c}1 \\
(2.2 \%)\end{array}$ & $\begin{array}{c}7 \\
(15.5 \%)\end{array}$ & $\begin{array}{c}83 \\
(93.3 \%)\end{array}$ & - & $\begin{array}{c}6 \\
(6.7 \%)\end{array}$ \\
\hline & Drawing hand & $\begin{array}{c}34 \\
(75.6 \%)\end{array}$ & $\begin{array}{c}5 \\
(11.1 \%)\end{array}$ & $\begin{array}{c}6 \\
(13.3 \%)\end{array}$ & $\begin{array}{c}75 \\
(84.3 \%)\end{array}$ & $\begin{array}{c}9 \\
(10.1 \%)\end{array}$ & $\begin{array}{c}5 \\
(5.6 \%)\end{array}$ \\
\hline & $\begin{array}{l}\text { Throwing } \\
\text { hand }\end{array}$ & $\begin{array}{c}21 \\
(46.7 \%)\end{array}$ & $\begin{array}{c}21 \\
(46.7 \%)\end{array}$ & $\begin{array}{c}3 \\
(6.7 \%)\end{array}$ & $\begin{array}{c}38 \\
(42.7 \%)\end{array}$ & $\begin{array}{c}43 \\
(48.3 \%)\end{array}$ & $\begin{array}{c}8 \\
(9 \%)\end{array}$ \\
\hline & $\begin{array}{l}\text { Hand using } \\
\text { computer } \\
\text { mouse }\end{array}$ & $\begin{array}{c}36 \\
(80 \%)\end{array}$ & $\begin{array}{c}6 \\
(13.3 \%)\end{array}$ & $\begin{array}{c}3 \\
(6.7 \%)\end{array}$ & $\begin{array}{c}74 \\
(83.3 \%)\end{array}$ & $\begin{array}{c}12 \\
(13.5 \%)\end{array}$ & $\begin{array}{c}3 \\
(3.4 \%)\end{array}$ \\
\hline
\end{tabular}


Table 2

Handedness groupings of the participants in the two groups, broken down by sex.

(RH=Right-handed, $L H=$ Left-handed, $M H=$ Mixed-handed $)$ for Study 1

\begin{tabular}{|c|c|c|c|c|c|c|c|}
\hline & & \multicolumn{3}{|c|}{$\begin{array}{l}\text { Learning Difficulties in } \\
\text { mathematics }\end{array}$} & \multicolumn{3}{|c|}{ Typically achieving } \\
\hline & & Males & Females & Total & Males & Females & Total \\
\hline \multirow{2}{*}{$\begin{array}{l}\text { Right } \\
\text { vs. Left } \\
\text { Classific } \\
\text { ation }\end{array}$} & RH & $\begin{array}{c}16 \\
(42.11 \%)\end{array}$ & $\begin{array}{c}22 \\
(57.89 \\
\%)\end{array}$ & 38 & $\begin{array}{c}39 \\
(48.15 \%)\end{array}$ & $\begin{array}{c}42 \\
(51.85 \%)\end{array}$ & 81 \\
\hline & LH & $3(42.96 \%)$ & $\begin{array}{c}4 \\
(57.14 \% \\
)\end{array}$ & 7 & $3(37.5 \%)$ & $5(62.5 \%)$ & 8 \\
\hline \multirow{3}{*}{$\begin{array}{l}\text { Right } \\
\text { vs. } \\
\text { Mixed } \\
\text { vs. Left } \\
\text { Classific } \\
\text { ation }\end{array}$} & RH & $\begin{array}{c}16 \\
(43.24 \%)\end{array}$ & $\begin{array}{c}21 \\
(56.76 \% \\
)\end{array}$ & 37 & $\begin{array}{c}36 \\
(47.37 \%)\end{array}$ & $\begin{array}{c}40 \\
(52.63 \%)\end{array}$ & 76 \\
\hline & MH & $1(33.33 \%)$ & $\begin{array}{c}2 \\
(66.6 \%)\end{array}$ & 3 & $4(44.44 \%)$ & $\begin{array}{c}5 \\
(55.56 \%)\end{array}$ & 9 \\
\hline & LH & $2(40 \%)$ & $3(60 \%)$ & 5 & $2(50 \%)$ & $2(50 \%)$ & 4 \\
\hline $\begin{array}{l}\text { Degree } \\
\text { of } \\
\text { handed } \\
\text { ness } \\
\text { (mean } \pm \\
\text { SD) }\end{array}$ & & $1.32 \pm 2.36$ & $\begin{array}{l}1.77 \pm \\
2.12\end{array}$ & $\begin{array}{l}1.58 \\
\pm \\
2.21\end{array}$ & $1.12 \pm 1.55$ & $\begin{array}{l}1.30 \pm \\
1.55\end{array}$ & $\begin{array}{l}1.21 \\
\pm \\
1.54\end{array}$ \\
\hline
\end{tabular}


Table 3

Handedness data for the MLD and TA groups, broken down by sex for Study 2

\begin{tabular}{|c|c|c|c|c|c|c|}
\hline & \multicolumn{3}{|c|}{$\begin{array}{c}\text { Mathematical Learning } \\
\text { Difficulties }\end{array}$} & \multicolumn{3}{|c|}{ Typically Achieving } \\
\hline & Right & Left & Total & Right & Left & Total \\
\hline Male & $\begin{array}{c}165 \\
(89.67 \%)\end{array}$ & $\begin{array}{c}19 \\
(10.33 \%)\end{array}$ & 184 & $\begin{array}{c}512 \\
(86.78 \%)\end{array}$ & $\begin{array}{c}78 \\
(13.22 \%)\end{array}$ & 590 \\
\hline Female & $\begin{array}{c}237 \\
(90.80 \%)\end{array}$ & $\begin{array}{c}24 \\
(9.20 \%)\end{array}$ & 261 & $\begin{array}{c}779 \\
(90.79)\end{array}$ & $\begin{array}{c}79 \\
(9.21 \%)\end{array}$ & 858 \\
\hline Total & $\begin{array}{c}402 \\
(90.33 \%)\end{array}$ & $\begin{array}{c}43 \\
(9.66 \%)\end{array}$ & 445 & $\begin{array}{c}1291 \\
(89.16 \%)\end{array}$ & $\begin{array}{c}157 \\
(10.84 \%)\end{array}$ & 1448 \\
\hline
\end{tabular}


Table 4

Handedness and sex in individuals with severe mathematical difficulties for Study 2.

\begin{tabular}{|l|l|l|l|}
\hline$M A<-1.75$ SD & Right & Left & Total \\
\hline Male & $67(89.33 \%)$ & $8(10.67 \%)$ & 75 \\
\hline Female & $71(87.65 \%)$ & $10(12.35 \%)$ & 81 \\
\hline Total & $138(88.46 \%)$ & $18(11.54 \%)$ & $\mathbf{1 5 6}$ \\
\hline
\end{tabular}


HAND PREFERENCE AND MLD

Table 5

Handedness groupings of the participants in the two groups, broken down by sex for Study 3

\begin{tabular}{cccccccccc} 
& \multicolumn{3}{c}{ Not at risk of MLD } & \multicolumn{5}{c}{ At risk of MLD } \\
\cline { 2 - 9 } & $\begin{array}{c}\text { Right- } \\
\text { handed }\end{array}$ & $\begin{array}{c}\text { Left- } \\
\text { handed }\end{array}$ & $\begin{array}{c}\text { Incon- } \\
\text { sistent }\end{array}$ & $\begin{array}{c}\text { Tota } \\
\mathbf{l}\end{array}$ & $\begin{array}{c}\text { Right- } \\
\text { handed }\end{array}$ & $\begin{array}{c}\text { Left- } \\
\text { handed }\end{array}$ & $\begin{array}{c}\text { Incon- } \\
\text { sistent }\end{array}$ & $\begin{array}{c}\text { Tota } \\
\text { I }\end{array}$ \\
\hline Male & 67 & 1 & 1 & 69 & 9 & 1 & 0 & 10 \\
& $(97.10 \%)$ & $(1.45 \%)$ & $(1.45 \%)$ & & $(90 \%)$ & $(10 \%)$ & $(0 \%)$ & \\
Female & 63 & 2 & 0 & 65 & 8 & 1 & 0 & 9 \\
& $(96.92 \%)$ & $(3.08 \%)$ & $(0 \%)$ & & $(88.89 \%)$ & $(11.11 \%)$ & $(0 \%)$ & \\
Total & 130 & 3 & 1 & 134 & 17 & 2 & 0 & 19 \\
& $(97.01 \%)$ & $(2.24 \%)$ & $(0.75 \%)$ & & $(89.47 \%)$ & $(10.53 \%)$ & $(0 \%)$ & \\
\hline
\end{tabular}


Table 6

Descriptive statistics for children's age, degree of hand skill, control variables, and math ability score grouped by risk of MLD and handedness for Study 3

Right- handed Left-handed Right-handed Left- handed

\begin{tabular}{lcccc}
\hline Age in months & 65.82 & 59.33 & 62.82 & 69.50 \\
$\begin{array}{l}\text { Degree of hand } \\
\text { skill }\end{array}$ & .23 & -.14 & .27 & .07 \\
$\begin{array}{l}\text { Visual working } \\
\text { memory span }\end{array}$ & 3.33 & 2.33 & 1.59 & 2.50 \\
$\begin{array}{l}\text { Cognitive abilities } \\
\text { Math ability score }\end{array}$ & 13.78 & 12.67 & 9.71 & 17.00 \\
& 85.87 & 69.67 & 38.71 & 54.50 \\
\hline
\end{tabular}


HAND PREFERENCE AND MLD 
Table 7

Details of studies included in the meta-analyses. MLD = individuals with mathematical learning difficulties, TA = typically achieving individuals

\begin{tabular}{|c|c|c|c|c|c|c|c|c|c|c|c|}
\hline Study & $\begin{array}{c}\mathrm{N} \\
\text { (total) }\end{array}$ & $\begin{array}{c}\mathrm{N} \\
(\mathrm{MLD})\end{array}$ & $\begin{array}{c}\mathbf{N} \\
\text { (TA) }\end{array}$ & $\begin{array}{l}\text { Mean } \\
\text { Age } \\
\text { MLD } \\
\text { (years) }\end{array}$ & $\begin{array}{c}\text { Mean } \\
\text { Age TA } \\
\text { (years) }\end{array}$ & $\begin{array}{l}\text { Measure of } \\
\text { Handedness }\end{array}$ & $\begin{array}{c}\text { Classification } \\
\text { of Handedness }\end{array}$ & $\begin{array}{c}\text { Diagnosis of } \\
\text { MLD }\end{array}$ & $\begin{array}{l}\text { Handedness } \\
\text { MLD Right / } \\
\text { Left/Mixed/ } \\
\text { Non-right }\end{array}$ & $\begin{array}{c}\text { Handedness } \\
\text { TA Right / } \\
\text { Left/Mixed/ } \\
\text { Non-right }\end{array}$ & Notes \\
\hline $\begin{array}{l}\text { Study } 1 \\
(2019)\end{array}$ & 134 & 45 & 89 & 9.79 & 9.75 & $\begin{array}{l}\text { 4-item } \\
\text { inventory }\end{array}$ & $\begin{array}{l}\text { Right-handed, } \\
\text { Left-handed, } \\
\text { Mixed }\end{array}$ & $\begin{array}{l}\text { Mathemati } \\
\text { cal } \\
\text { Learning } \\
\text { Difficulties } \\
\text { (MLD) }\end{array}$ & $37 / 5 / 3 / 8$ & $76 / 4 / 9 / 13$ & - \\
\hline $\begin{array}{l}\text { Study } 2 \\
(2019)\end{array}$ & 2,109 & 445 & $\begin{array}{l}1,66 \\
4\end{array}$ & 11.14 & 11.27 & $\begin{array}{l}\text { Self-reported } \\
\text { writing hand }\end{array}$ & $\begin{array}{l}\text { Right-handed, } \\
\text { Left-handed, } \\
\text { Inconsistent }\end{array}$ & $\begin{array}{l}\text { Mathemati } \\
\text { cal } \\
\text { Learning } \\
\text { Difficulties } \\
\text { (MLD) }\end{array}$ & $391 / 45 / 3 / 48$ & $\begin{array}{l}1291 / 157 / 12 \\
/ / \\
169\end{array}$ & - \\
\hline $\begin{array}{l}\text { Study } 3 \\
(2019)\end{array}$ & 153 & 19 & 134 & 5.5 & 5.27 & $\begin{array}{l}\text { Observation } \\
\text { of writing } \\
\text { hand \& } \\
\text { tapping speed }\end{array}$ & $\begin{array}{l}\text { Right-handed, } \\
\text { Left-handed, } \\
\text { Inconsistent }\end{array}$ & $\begin{array}{l}\text { Mathemati } \\
\text { cal } \\
\text { Learning } \\
\text { Difficulties } \\
\text { (MLD) }\end{array}$ & $12 / 2 / 0 / 2$ & $130 / 3 / 1 / 4$ & - \\
\hline $\begin{array}{l}\text { Ashkenazi, \& } \\
\text { Henik (2010) }\end{array}$ & 24 & 12 & 12 & 24 & 24.3 & - & $\begin{array}{l}\text { Right-handed, } \\
\text { Left-handed }\end{array}$ & $\begin{array}{l}\text { Developme } \\
\text { ntal } \\
\text { Dyscalculia }\end{array}$ & 8/4/-/- & 8/4/-/- & - \\
\hline
\end{tabular}


HAND PREFERENCE AND MLD

\begin{tabular}{|c|c|c|c|c|c|c|c|c|c|c|c|}
\hline & & & & \multicolumn{8}{|c|}{-DD } \\
\hline Bucca (2018) & 144 & 144 & - & - & - & $\begin{array}{l}\text { Edinburgh } \\
\text { Handedness } \\
\text { Inventory } \\
\text { (Oldfield, } \\
\text { 1971) }\end{array}$ & $\begin{array}{l}\text { Right-handed, } \\
\text { Left-handed }\end{array}$ & Dyscalculia & $124 / 20 /-/-$ & - & $\begin{array}{l}\text { There are four } \\
\text { other groups } \\
\text { different from } \\
\text { TA. }\end{array}$ \\
\hline $\begin{array}{l}\text { Greiffenstein, } \\
\& \text { Baker } \\
(2002)\end{array}$ & 45 & 45 & - & 28.57 & - & - & $\begin{array}{l}\text { Right-handed, } \\
\text { Non-right- } \\
\text { handed }\end{array}$ & $\begin{array}{l}\text { Arithmetic } \\
\text { Deficiency- } \\
\text { AD }\end{array}$ & $27 /-/-/ 18$ & - & $\begin{array}{l}\text { There are two } \\
\text { more groups } \\
\text { of } \\
\text { participants: } \\
\text { reading } \\
\text { deficiency } \\
\text { (RD) and dual } \\
\text { deficiency } \\
\text { (RAD). All } \\
\text { participants } \\
\text { were drawn } \\
\text { from a sample } \\
\text { of } 267 \text { adults } \\
\text { referred for } \\
\text { neuropsycholo } \\
\text { gical testing } \\
\text { for work- } \\
\text { adjustment } \\
\text { difficulties. }\end{array}$ \\
\hline $\begin{array}{l}\text { Jastrzebski, } \\
\text { Crewther, \& } \\
\text { Crewther } \\
\text { (2015) }\end{array}$ & 19 & 5 & 14 & $19-33$ & 24 & - & - & $\begin{array}{l}\text { Mathemati } \\
\text { cally } \\
\text { impaired }\end{array}$ & $4 / 1 /-/-$ & $12 / 2 /-/-$ & $\begin{array}{l}\text { All } \\
\text { participants } \\
\text { are females. }\end{array}$ \\
\hline
\end{tabular}


HAND PREFERENCE AND MLD

\begin{tabular}{|c|c|c|c|c|c|c|c|c|c|c|c|}
\hline $\begin{array}{l}\text { Jovanović, } \\
\text { Purić, \& } \\
\text { Ignjatović- } \\
\text { Ristić (2014) }\end{array}$ & 140 & 83 & 57 & - & - & $\begin{array}{l}\text { Observation } \\
\text { of } 12 \text { tasks of } \\
\text { dominant } \\
\text { laterality of } \\
\text { upper } \\
\text { extremities }\end{array}$ & $\begin{array}{l}\text { Right-handed, } \\
\text { Left-handed, } \\
\text { Ambidextrous }\end{array}$ & $\begin{array}{l}\text { Developme } \\
\text { ntal } \\
\text { Dyscalculia } \\
\text {-DD }\end{array}$ & 76/7/-/- & 53/4/-/- & - \\
\hline $\begin{array}{l}\text { Kovas, } \\
\text { Giampietro, } \\
\text { Viding, } \\
\text { Brammer, } \\
\text { Barker, ... \& } \\
\text { Plomin } \\
(2009)\end{array}$ & 13 & 13 & - & 10 & - & - & $\begin{array}{l}\text { Right-handed, } \\
\text { Left-handed }\end{array}$ & $\begin{array}{l}\text { Low } \\
\text { mathematic } \\
\text { al ability }\end{array}$ & $11 / 2 /-/-$ & - & $\begin{array}{l}\text { There is one } \\
\text { more group of } \\
\text { participants } \\
\text { with high } \\
\text { mathematical } \\
\text { ability. }\end{array}$ \\
\hline $\begin{array}{l}\text { Kucian } \\
\text { (unpublished } \\
\text { 2018) }\end{array}$ & 52 & 28 & 24 & 12.06 & 11.19 & $\begin{array}{l}\text { Edinburgh } \\
\text { Handedness } \\
\text { Inventory } \\
\text { (Oldfield, } \\
\text { 1971) }\end{array}$ & $\begin{array}{l}\text { Right-handed, } \\
\text { Left-handed, } \\
\text { Ambidextrous }\end{array}$ & $\begin{array}{l}\text { Developme } \\
\text { ntal } \\
\text { Dyscalculia } \\
\text {-DD }\end{array}$ & $23 / 3 / 2 /-$ & 19/1/4/- & - \\
\hline $\begin{array}{l}\text { Kucian,Ashk } \\
\text { enazi, } \\
\text { Hänggi, } \\
\text { Rotzer, } \\
\text { Jäncke, } \\
\text { Martin, \& } \\
\text { von Aster } \\
\text { (2014) }\end{array}$ & 30 & 15 & $\begin{array}{l}15(8 \\
+7)^{*}\end{array}$ & 10 & 10.1 & $\begin{array}{l}\text { Edinburgh } \\
\text { Handedness } \\
\text { Inventory } \\
\text { (Oldfield, } \\
\text { 1971) }\end{array}$ & $\begin{array}{l}\text { Right-handed, } \\
\text { Left-handed, } \\
\text { Ambidextrous }\end{array}$ & $\begin{array}{l}\text { Developme } \\
\text { ntal } \\
\text { Dyscalculia } \\
\text {-DD }\end{array}$ & $12 / 1 / 2 /-$ & $14 / 0 / 1 /-$ & $\begin{array}{l}\text { Seven TA } \\
\text { children were } \\
\text { recruited from } \\
\text { two other } \\
\text { studies } \\
\text { running at the } \\
\text { Center for MR } \\
\text { Research of } \\
\text { the University } \\
\text { Children's }\end{array}$ \\
\hline
\end{tabular}


HAND PREFERENCE AND MLD

\begin{tabular}{|c|c|c|c|c|c|c|c|c|c|c|c|}
\hline & & & & & & & & & & & $\begin{array}{l}\text { Hospital } \\
\text { Zurich. }\end{array}$ \\
\hline $\begin{array}{l}\text { Kucian, } \\
\text { Grond, } \\
\text { Rotzer, } \\
\text { Henzi, } \\
\text { Schönmann, } \\
\text { Plangger,. .... } \\
\text { \& von Aster } \\
\text { (2011a) }\end{array}$ & 32 & 16 & 16 & 9.5 & 9.5 & $\begin{array}{l}\text { Edinburgh } \\
\text { Handedness } \\
\text { Inventory } \\
\text { (Oldfield, } \\
\text { 1971) }\end{array}$ & $\begin{array}{l}\text { Right-handed, } \\
\text { Left-handed, } \\
\text { Ambidextrous }\end{array}$ & $\begin{array}{l}\text { Developme } \\
\text { ntal } \\
\text { Dyscalculia } \\
\text {-DD }\end{array}$ & $14 / 1 / 1 /-$ & $12 / 0 / 4 /-$ & - \\
\hline $\begin{array}{l}\text { Lafay et al. } \\
(2017)\end{array}$ & 61 & 24 & 37 & 9.01 & 8.94 & Not reported & $\begin{array}{l}\text { Right-handed, } \\
\text { Left-handed }\end{array}$ & $\begin{array}{l}\text { Mathemati } \\
\text { cs } \\
\text { Difficulties } \\
\text { (MD) } \\
\text { Developme } \\
\text { ntal } \\
\text { Dyscalculia } \\
\text { (DD) }\end{array}$ & $19 / 5 /-/ 5$ & $31 / 6 /-/ 6$ & - \\
\hline $\begin{array}{l}\text { McCaskey } 1 \\
\text { (unpublished } \\
\text { 2018) }\end{array}$ & 35 & 22 & 13 & 9.67 & 9.42 & $\begin{array}{l}\text { Edinburgh } \\
\text { Handedness } \\
\text { Inventory } \\
\text { (Oldfield, } \\
\text { 1971) }\end{array}$ & $\begin{array}{l}\text { Right-handed, } \\
\text { Left-handed, } \\
\text { Ambidextrous }\end{array}$ & $\begin{array}{l}\text { Developme } \\
\text { ntal } \\
\text { Dyscalculia } \\
\text {-DD }\end{array}$ & $13 / 3 / 6 / 9$ & $7 / 1 / 5 / 6$ & $\begin{array}{l}\text { Includes all } \\
\text { the } \\
\text { participants } \\
\text { from the } \\
\text { longitudinal } \\
\text { study McCask } \\
\text { ey et al. } \\
\text { (2018). Most } \\
\text { of those } \\
\text { individuals }\end{array}$ \\
\hline
\end{tabular}




\begin{tabular}{|c|c|c|c|c|c|c|c|c|c|c|c|}
\hline & & & & & & & & & & & $\begin{array}{l}\text { also } \\
\text { participated } \\
\text { in McCaskey } \\
\text { et al. (2017). }\end{array}$ \\
\hline $\begin{array}{l}\text { McCaskey } 2 \\
\text { (unpublished } \\
\text { 2018) }\end{array}$ & 10 & 3 & 7 & 15.13 & 13.5 & $\begin{array}{l}\text { Edinburgh } \\
\text { Handedness } \\
\text { Inventory } \\
\text { (Oldfield, } \\
\text { 1971) }\end{array}$ & $\begin{array}{l}\text { Right-handed, } \\
\text { Left-handed, } \\
\text { Ambidextrous }\end{array}$ & $\begin{array}{l}\text { Developme } \\
\text { ntal } \\
\text { Dyscalculia } \\
\text {-DD }\end{array}$ & $3 /-/-/-$ & $6 /-/ 1 / 1$ & $\begin{array}{l}\text { Includes only } \\
\text { participants } \\
\text { that were } \\
\text { additionally } \\
\text { measured for } \\
\text { the McCaskey } \\
\text { et al. (2017) } \\
\text { study. }\end{array}$ \\
\hline $\begin{array}{l}\text { Price, } \\
\text { Holloway, } \\
\text { Räsänen, } \\
\text { Vesterinen, } \\
\text { \& Ansari } \\
\text { (2007) }\end{array}$ & 16 & 8 & 8 & - & - & - & - & $\begin{array}{l}\text { Developme } \\
\text { ntal } \\
\text { Dyscalculia } \\
\text {-DD }\end{array}$ & 8/-/-/- & 8/-/-/- & - \\
\hline $\begin{array}{l}\text { Rotzer, } \\
\text { Loenneker, } \\
\text { Kucian, } \\
\text { Martin, } \\
\text { Klaver, \& } \\
\text { Von Aster } \\
(2009)\end{array}$ & 21 & 10 & 11 & 10.4 & 10.2 & $\begin{array}{l}\text { Edinburgh } \\
\text { Handedness } \\
\text { Inventory } \\
\text { (Oldfield, } \\
\text { 1971) }\end{array}$ & $\begin{array}{l}\text { Right-handed, } \\
\text { Left-handed, } \\
\text { Ambidexter }\end{array}$ & $\begin{array}{l}\text { Developme } \\
\text { ntal } \\
\text { Dyscalculia } \\
\text {-DD }\end{array}$ & $5 / 1 / 4 /-$ & $9 / 0 / 2 /-$ & - \\
\hline $\begin{array}{l}\text { Rubinsten, \& } \\
\text { Henik (2006) }\end{array}$ & 34 & 17 & 17 & 23.9 & 22.1 & - & $\begin{array}{l}\text { Right-handed, } \\
\text { Left-handed }\end{array}$ & $\begin{array}{l}\text { Developme } \\
\text { ntal } \\
\text { Dyscalculia }\end{array}$ & $15 / 2 /-/-$ & $14 / 3 /-/-$ & $\begin{array}{l}\text { There is one } \\
\text { more group of } \\
\text { participants }\end{array}$ \\
\hline
\end{tabular}




\begin{tabular}{|c|c|c|c|c|c|c|c|c|c|c|c|}
\hline & & & & & & & & $-\mathrm{DD}$ & & & $\begin{array}{l}\text { with the } \\
\text { diagnosis of } \\
\text { dyslexia. }\end{array}$ \\
\hline $\begin{array}{l}\text { Shalev, } \\
\text { Manor, Amir, } \\
\text { Wertman- } \\
\text { Elad, \& } \\
\text { Gross-Tsur } \\
\text { (1995) }\end{array}$ & 12 & 12 & - & 11.5 & - & - & $\begin{array}{l}\text { Right-handed, } \\
\text { Left-handed }\end{array}$ & $\begin{array}{l}\text { Developme } \\
\text { ntal } \\
\text { Dyscalculia } \\
\text {-DD }\end{array}$ & $8 / 4 /-/-$ & & $\begin{array}{l}\text { Total number } \\
\text { of participants } \\
\text { is } 25 . \text { We } \\
\text { included only } \\
\text { participants } \\
\text { with } \\
\text { dyscalculia } \\
\text { without } \\
\text { ADHD. }\end{array}$ \\
\hline $\begin{array}{l}\text { Skeide et al. } \\
(2018)\end{array}$ & 24 & 12 & 12 & 8.88 & 8.7 & Not reported & $\begin{array}{l}\text { Right-handed, } \\
\text { Left-handed }\end{array}$ & $\begin{array}{l}\text { Low } \\
\text { mathematic } \\
\text { al ability } \\
\text { (LM) }\end{array}$ & $12 / 0 /-/ 0$ & $12 / 0 /-/ 0$ & $\begin{array}{c}\text { There are } \\
\text { three other } \\
\text { groups } \\
\text { different from } \\
\text { TA. }\end{array}$ \\
\hline $\begin{array}{l}\text { Spellacy, \& } \\
\text { Peter (1978) }\end{array}$ & 14 & 14 & - & 10.15 & - & $\begin{array}{l}\text { Lateral } \\
\text { dominance } \\
\text { examination } \\
\text { (Spreen \& } \\
\text { Gaddes, } \\
\text { 1969). }\end{array}$ & $\begin{array}{l}\text { Dextral/D- } \\
\text { Non } \\
\text { Dextral/ND }\end{array}$ & $\begin{array}{l}\text { Developme } \\
\text { ntal } \\
\text { Dyscalculia } \\
\text {-DD }\end{array}$ & $6 /-/-/ 8$ & - & $\begin{array}{l}\text { The DD } \\
\text { participants } \\
\text { are separated } \\
\text { in two groups: } \\
\text { good reading } \\
\text { (G) and pour } \\
\text { reading (P) } \\
\text { group, which } \\
\text { were merged } \\
\text { for the } \\
\text { purposes of }\end{array}$ \\
\hline
\end{tabular}


HAND PREFERENCE AND MLD

\begin{tabular}{|c|c|c|c|c|c|c|c|c|c|c|c|}
\hline & & & & & & & & & & & $\begin{array}{l}\text { the present } \\
\text { analysis. }\end{array}$ \\
\hline $\begin{array}{l}\text { Zergiotis } \\
(2004)\end{array}$ & 25 & 25 & - & 8.7 & - & Athena Test & $\begin{array}{l}\text { Right-handed, } \\
\text { Left-handed, } \\
\text { Ambidextrous }\end{array}$ & $\begin{array}{l}\text { Mathemati } \\
\text { cal } \\
\text { Learning } \\
\text { Difficulties } \\
\text {-MLD }\end{array}$ & $21 /-/ 4 /-$ & - & $\begin{array}{l}\text { There is a TA } \\
\text { group of } 96 \\
\text { participants, } \\
\text { but there is no } \\
\text { information } \\
\text { about their } \\
\text { handedness } \\
\text { reported. }\end{array}$ \\
\hline
\end{tabular}

